\title{
Intraperitoneal Lavage with Crocus sativus Prevents Postoperative-Induced Peritoneal Adhesion in a Rat Model: Evidence from Animal and Cellular Studies
}

\author{
Pouria Rahmanian-Devin, ${ }^{1}$ Hassan Rakhshandeh $\mathbb{D}^{2}$ Vafa Baradaran Rahimi, ${ }^{2}$ \\ Zahra Sanei-Far, ${ }^{2}$ Maede Hasanpour, ${ }^{3}$ Arghavan Memarzia, ${ }^{4}$ Mehrdad Iranshahi, ${ }^{3}$ \\ and Vahid Reza Askari $\left.{ }^{5}\right)^{5,6,7}$ \\ ${ }^{1}$ Department of Pharmaceutics, School of Pharmacy, Mashhad University of Medical Sciences, Mashhad, Iran \\ ${ }^{2}$ Pharmacological Research Center of Medicinal Plants, Mashhad University of Medical Sciences, Mashhad, Iran \\ ${ }^{3}$ Biotechnology Research Center, Pharmaceutical Technology Institute, Mashhad University of Medical Sciences, Mashhad, Iran \\ ${ }^{4}$ Department of Physiology, Faculty of Medicine, Mashhad University of Medical Sciences, Mashhad, Iran \\ ${ }^{5}$ Applied Biomedical Research Center, Mashhad University of Medical Sciences, Mashhad, Iran \\ ${ }^{6}$ Department of Pharmaceutical Sciences in Persian Medicine, School of Persian and Complementary Medicine, Mashhad University \\ of Medical Sciences, Mashhad, Iran \\ ${ }^{7}$ Department of Persian Medicine, School of Persian and Complementary Medicine, Mashhad University of Medical Sciences, \\ Mashhad, Iran
}

Correspondence should be addressed to Vahid Reza Askari; askariv@mums.ac.ir

Received 31 August 2021; Revised 15 November 2021; Accepted 26 November 2021; Published 16 December 2021

Academic Editor: Xun Cui

Copyright (c) 2021 Pouria Rahmanian-Devin et al. This is an open access article distributed under the Creative Commons Attribution License, which permits unrestricted use, distribution, and reproduction in any medium, provided the original work is properly cited.

\footnotetext{
Postoperative peritoneal adhesions are considered the major complication following abdominal surgeries. The primary clinical complications of peritoneal adhesion are intestinal obstruction, infertility, pelvic pain, and postoperative mortality. In this study, regarding the anti-inflammatory and antioxidant activities of Crocus sativus, we aimed to evaluate the effects of Crocus sativus on the prevention of postsurgical-induced peritoneal adhesion. Male Wistar-Albino rats were used to investigate the preventive effects of C. sativus extract $(0.5 \%, 0.25 \%$ and $0.125 \% \mathrm{w} / \mathrm{v})$ against postsurgical-induced peritoneal adhesion compared to pirfenidone (PFD, 7.5\% w/v). We also investigated the protective effects of PFD $(100 \mu \mathrm{g} / \mathrm{ml})$ and C. sativus extract (100, 200, and $400 \mu \mathrm{g} / \mathrm{ml}$ ) in TGF- $\beta 1$-induced fibrotic macrophage polarization. The levels of cell proliferation and oxidative, antioxidative, inflammatory and anti-inflammatory, fibrosis, and angiogenesis biomarkers were evaluated both in vivo and in vitro models. C. sativus extract ameliorates postoperational-induced peritoneal adhesion development by attenuating oxidative stress [malondialdehyde (MDA)]; inflammatory mediators [interleukin- (IL-) 6, tumour necrosis factor- (TNF-) $\alpha$, and prostaglandin $\mathrm{E}_{2}\left(\mathrm{PGE}_{2}\right)$ ]; fibrosis [transforming growth factor- (TGF-) $\beta 1$, IL-4, and plasminogen activator inhibitor (PAI)]; and angiogenesis [vascular endothelial growth factor (VEGF)] markers, while propagating antioxidant [glutathione (GSH)], anti-inflammatory (IL-10), and fibrinolytic [tissue plasminogen activator (tPA)] markers and tPA/PAI ratio. In a cellular model, we revealed that the extract, without any toxicity, regulated the levels of cell proliferation and inflammatory (TNF- $\alpha$ ), angiogenesis (VEGF), anti-inflammatory (IL-10), M1 [inducible nitric oxide synthase (iNOS)] and M2 [arginase-1 (Arg 1)] biomarkers, and iNOS/Arg-1 ratio towards antifibrotic M1 phenotype of macrophage, in a concentration-dependent manner. Taken together, the current study indicated that C. sativus reduces peritoneal adhesion formation by modulating the macrophage polarization from M2 towards M1 cells.
} 


\section{Introduction}

Postoperative peritoneal adhesions are considered the major complication after abdominal surgery. Peritoneal adhesion is an abnormal connective tissue that occurs between two tissues that have been damaged during the surgery $[1,2]$. The peritoneum gets harmed and forms a temporary matrix during the surgery. After several hours, this provisional matrix becomes a clot, which can be destroyed by various factors such as macrophages and fibrinolysin enzymes.

Following the clot formation after 72 hours, the fibroblasts of the underlying tissues migrate into the clot and provide a field for forming sticky tissue [3, 4]. It has been emphasised that inflammation, free radicals, hypoxia, coagulation, and fibrinolysis are the main pathophysiological reasons responsible for forming peritoneal adhesion $[2,5]$.

Plasminogen activator (PA) is a protease that converts plasminogen into plasmin and prevents mesothelial cell adhesion [3]. Numerous inflammatory cytokines are released following the peritoneal injury, such as interferon-gamma (IFN- $\gamma$ ), interleukin-4 (IL-4), IL-10, IL-6, tumour necrosis factor-alpha (TNF- $\alpha$ ), and prostaglandin E2 (PGE-2) [6-9]. These inflammatory cytokines play an essential role in the development of peritoneal adhesion. Transforming growth factor-beta (TGF- $\beta$ ) is expressed by adhesion fibroblasts and mesothelial cells, which lead to adhesion formation and fibrosis $[7,10]$. Additionally, vascular endothelial growth factor (VEGF) is another important marker in angiogenesis, wound healing, and adhesion formation $[2,11]$.

The surgical technique is the first method for adhesion treatment; however, it is insufficient alone [12]. Other therapeutic approaches have been studied, such as barrier therapy $[13,14]$ and gene therapy [15]. However, there is still no approved method for the treatment or prevention of adhesion, although a high prevalence of postoperative adhesions.

Crocus sativus (C. sativus), popularly named C. sativus, is a small plant belonging to Iridaceae. Crocin, crocetin, and safranal are the major ingredients of C. sativus [16]. Several pharmacological properties of $C$. sativus have been reported, including the antioxidant $[17,18]$, anticancer, anti-inflammatory $[19,20]$, anti-ischemia, and cardioprotective $[21,22]$ effects.

To our knowledge, there is no study evaluating the protective effects of $C$. sativus extract on preventing postoperative intra-abdominal adhesions. Therefore, in the present study, we aimed to determine the anti-inflammatory and antioxidant effects of Crocus sativus on the formation and prevention of postoperative abdominal adhesions in a rat model of peritoneal adhesion.

\section{Material and Methods}

2.1. Drugs and Chemicals. Ethanol, methanol, acetonitrile, formic acid, dimethyl sulfoxide, ammonium chloride, $\mathrm{HCl}$, and dexamethasone were purchased from Sigma ${ }^{\circledR}$, USA. Ketamine and xylazine were obtained from ChemiDarou ${ }^{\circledR}$, Iran. The injectable normal saline serum was also prepared from Samen ${ }^{\circledR}$, Iran. Furthermore, enzyme-linked immunosorbent assay (ELISA) kits of IL-4, IL-10, IL-6, TNF- $\alpha$,
$\mathrm{PGE}_{2}$, TGF- $\beta$, tissue plasminogen activator (tPA), and plasminogen activator inhibitor (PAI) and VEGF were purchased from Bender Med ${ }^{\circledR}$, Germany. Dulbecco's modified Eagle's medium/F12 (DMEM/F12) culture media, fetal bovine serum (FBS), penicillin plus streptomycin (pen/ strep), dimethyl sulfoxide (DMSO), and other chemicals used were of cell culture and analytical grade from SigmaAldrich (St. Louis, MO, USA). Recombinant mouse TGF$\beta 1$ (5231LC) was obtained from Cell Signaling Technology, Inc. The levels of malondialdehyde (MDA) as an oxidative marker and glutathione (GSH) as an antioxidative marker were measured using commercially available biochemistry kits $\left(\right.$ ZellBio $^{\circledR}$, Germany).

2.2. Preparation of C. sativus Extract. C. sativus was prepared from C. sativus farms of Qaen $\left(33^{\circ} 43^{\prime} 33.02^{\prime \prime} \mathrm{N} 59^{\circ} 11^{\prime} 21.65^{\prime \prime}\right.$ E, South Khorasan, Iran) and identified by the herbarium of Ferdowsi University of Mashhad (herbarium No. 293-03031). The $70 \% v / v$ hydroethanolic extract of C. sativus was prepared using the maceration method as described previously [23]. Briefly, $10 \mathrm{~g}$ of its ground petal stigma was incubated with $400 \mathrm{ml}$ of $70 \% v / v$ ethanol in a macerated extractor for $72 \mathrm{~h}$. The prepared extract was dried in a rotatory evaporator and stored at $-20^{\circ} \mathrm{C}$ until use.

2.3. High-Performance Liquid Chromatography- (HPLC-) Mass Spectrometry (MS) Apparatus and the Extracted Analysis. The LC-MS analysis was performed in an AB SCIEX QTRAP (Shimadzu) liquid chromatography coupled with a triple quadrupole Mass Spectrometer. Liquid chromatography separation was performed on a Supelco C18 $(15 \mathrm{~mm} \times 2.1 \mathrm{~mm} \times 3 \mu \mathrm{m})$ column. MS analysis was carried out in both negative and positive modes of ionisation to monitor as many ions as possible and to ensure that the most significant number of metabolites extracted from the C. sativus sample was detected. The analysis was done at a flow rate of $0.2 \mathrm{ml} / \mathrm{min}$. The gradient analysis started with $100 \%$ of $0.4 \%$ aqueous formic acid, isocratic conditions were maintained for $1 \mathrm{~min}$, and then a $14 \mathrm{~min}$ linear gradient to $40 \%$ acetonitrile with $0.4 \%$ formic acid was applied. From 14 to $35 \mathrm{~min}$, the acidified acetonitrile was increased to $100 \%$, followed by $5 \mathrm{~min}$ of $100 \%$ acidified acetonitrile and $5 \mathrm{~min}$ at the start conditions to reequilibrate the column. The mass spectra were acquired in a range of 100 to 1500 within the 45 minutes scan time. Mass feature extraction of the acquired LC-MS data and maximum detection of peaks was done using the MZmine analysis software package, version 2.3 .

\subsection{In Vivo Study}

2.4.1. Animals. Seventy male Wistar-Albino rats weighing $250 \pm 15 \mathrm{~g}$ ( six weeks old) were purchased from the animal laboratory unit of Faculty of Medicine, Mashhad University of Medical Sciences, Mashhad, Iran. Rats were housed in separated standard cages and ventilated room with a $12 / 12 \mathrm{~h}$ natural light-dark cycle, $60 \pm 3 \%$ humidity, and temperature of $21 \pm 2^{\circ} \mathrm{C}$. They had free access to food and taped water before and during the experiments. More appropriate hygiene was provided with continuous cleaning and removal 
TABle 1: Adhesion score categories according to Nair et al. [32].

\begin{tabular}{lr}
\hline Grades & Description of adhesive bands \\
\hline 0 & The complete absence of adhesions \\
1 & A single band of adhesion, between viscera or from viscera to the abdominal wall \\
2 & Two bands, either between viscera or from viscera to the abdominal wall \\
3 & More than two bands, between viscera or viscera to the abdominal wall or whole intestines forming a mass without being adherent \\
4 & to the abdominal wall
\end{tabular}

of faeces and spilt feeds from cages daily. All animals received human care in compliance with institutional guidelines.

2.4.2. Surgical Procedure. The ethical committee approved all animal-related procedures based on the guidelines of animal experiments in Mashhad University of Medical Sciences (ethical approved code http://IR.MUMS.fm.REC.1395.950309, Approval Date: 2017-03-01). The surgical method was accomplished as previously described $[2,24,25]$. In summary, animals received $100 \mathrm{mg} / \mathrm{kg}$ of ketamine and $10 \mathrm{mg} / \mathrm{kg}$ of xylazine intraperitoneally (i.p.) for anaesthesia. Following the skin's shaving and disinfection with alcohol and iodine solution, a three-centimeter incision was carefully done to reach the abdominal cavity. For intra-abdominal adhesion induction in rats, the peritoneal abrasion method was performed as one side of the middle abdominal incision was gently abraded using a soft sterilised paper polisher until the cecum provided an opaque presentation with fine petechiae. Afterwards, the peritoneum and the injured area were washed by $2 \mathrm{ml}$ of the extract or vehicle. After the intervention, the cecum was returned to the abdomen and abdomen wall then closed with 4-0 poly-gelatine suture. The procedure lasted to a maximum of 10 minutes. After surgery, rats were kept in their cages in the recovery room for seven days. All treatments were done by lavage in the abraded and whole surgical zone with a $2 \mathrm{ml}$ syringe. Furthermore, all rats received a single dose of antibiotic cefazolin $(300 \mathrm{mg} / \mathrm{kg}$ intramuscularly; i.m.) immediately after ending the surgery to prevent possible wound infection [26-28].

2.4.3. Experimental Groups. Seventy male Wistar rats were randomly divided into seven groups containing ten animals and grouped as follows:

(1) Group 1: normal-rats received neither surgical nor intervention procedures.

(2) Group 2: control-rats received surgical and peritoneal adhesion procedures without treatment.

(3) Group 3: vehicle-rats received surgical and peritoneal adhesion procedures and were treated with $2 \mathrm{ml}$ of the vehicle (the vehicle was sterilised distilled water containing $5 \% \mathrm{v} / \mathrm{v}$ of tween 80 [2]).

(4) Group 4: pirfenidone (PFD)—rats received surgical and peritoneal adhesion procedures and were treated with $2 \mathrm{ml}$ of the $7.5 \% \mathrm{w} / \mathrm{v}$ of PFD (approximately
$600 \mathrm{mg} / \mathrm{kg}$ or $150 \mathrm{mg} / \mathrm{animal}$ [29-31]), as positive control and the antifibrotic agent [29-31].

(5) Groups 5, 6, and 7: C. sativus extracts (S)-rats received surgical and peritoneal adhesion procedures and were treated with $2 \mathrm{ml}$ of either $0.125 \% w / v, 0$. $25 \% \mathrm{w} / \mathrm{v}$, or $0.5 \% \mathrm{w} / \mathrm{v}$ of the extract (approximately $12.5,25$, and $50 \mathrm{mg} / \mathrm{kg}$, respectively); the concentrations were chosen based on our preliminarily experiment.

2.4.4. Assessment of the Macroscopic Adhesion Grade. On the seventh day after the surgery, rats underwent a second laparotomy. Thereafter, two independent researchers blind to the protocol assessed the adhesion grading using the score published by Nair et al. [32] (Table 1). Additionally, cecum and peritoneal lavage fluid were collected for the measurement of inflammatory, fibrotic, and oxidative biomarkers.

2.4.5. Histological Assessment. In the current experiment, paraffin-embedded histological sections were stained by Masson's trichrome staining to assess the extent and distribution of fibrosis in rats' peritoneal tissue as described in previous studies [33-35]. In this regard, after removing formalin and washing with distilled water three times, the tissues were transferred to different alcohol concentrations (50-100\%) for some minutes. Tissue sections were observed with magnifications of $4 \mathrm{x}, 20 \mathrm{x}$, and $40 \mathrm{x}$ using a Nikon E1000 microscope (Japan) under bright-field optics.

2.4.6. Evaluation of Oxidative Parameters. The levels of $\mathrm{MDA}$, as an oxidative marker, and GSH, as an antioxidative marker, were measured in the peritoneal fluid using biochemistry kits (ZellBio ${ }^{\circledR}$, Germany) according to the manufacturer's manuals [36, 37].

2.4.7. Assessment of Inflammatory and Anti-Inflammatory Biomarkers. The levels of TNF- $\alpha$, IL- 6 , and $\mathrm{PGE}_{2}$, as inflammatory markers, and IL- 4 and IL-10, as anti-inflammatory markers, were evaluated in peritoneal lavage fluid by ELISA kits (Bender $\mathrm{Med}^{\circledR}$, Germany) according to the manufacturer's instruction [38, 39].

2.4.8. Evaluation of Fibrosis and Angiogenesis Biomarkers and Tissue Plasminogen Activator (tPA) and Plasminogen Activator Inhibitor (PAI). According to the manufacturer's instruction, the concentrations of fibrosis biomarkers (TGF- $\beta$ ) and angiogenesis marker (VEGF) of peritoneal fluid specimens were assessed by the relevant ELISA kits. 
TABLE 2: Peak assignment of metabolites in the hydroethanol extract of C. sativus (Crocus sativus L.) using LC-MS in the negative mode.

\begin{tabular}{|c|c|c|c|c|}
\hline Peak no. & Compound identification & $t_{\mathrm{R}}(\min )$ & {$[\mathrm{M}-1](m / z)$} & Ref. \\
\hline 1 & 4-( $\alpha$-D-glucopyranosyl)-2,6,6-trimethyl-1-cyclohexene-1-carboxaldehyde (picrocrocin) & 35.3 & 375.2 & {$[76]$} \\
\hline 2 & Crocetin di-( $\beta$-D-gentibiosyl) ester & 37.0 & 975.3 & [77] \\
\hline 3 & Crocetin ( $\beta$-D-glucosyl)-( $\beta$-D-neapolitanosyl) ester & 40.4 & 975.0 & {$[77]$} \\
\hline 4 & Crocin E & 40.4 & 489.4 & {$[76]$} \\
\hline 5 & Crocetin & 37.2 & 327.3 & {$[78]$} \\
\hline 6 & Dimethyl crocetin & 28.8 & 355.3 & {$[78]$} \\
\hline 7 & Quercetin 3-orutinosylrhamnoside & 29.4 & 755.7 & [77] \\
\hline 8 & Quercetin 3-O-rutinoside & 29.8 & 609.6 & [77] \\
\hline 9 & Isorhamnetin-3-orutinosylrhamnoside & 35.8 & 769.5 & [78] \\
\hline 10 & Narcissin & 42.1 & 623.8 & [78] \\
\hline 11 & Nepetalic acid & 35.2 & 183.1 & [79] \\
\hline 12 & Geranic acid & 30.6 & 167.0 & [79] \\
\hline 13 & Dihydrojasmonic acid, methyl ester & 32.7 & 225.0 & [79] \\
\hline 14 & Kaempferol 3-glucoside & 3.1 & 447.8 & {$[77]$} \\
\hline 15 & Angoluvarin & 16.5 & 483.42 & [79] \\
\hline 16 & Isococculidine & 5.1 & 284.6 & [79] \\
\hline 17 & 4-Apiosyl-glucoside & 1.1 & 593.3 & [79] \\
\hline
\end{tabular}

TABle 3: Peak assignment of metabolites in the hydroethanol extract of C. sativus (Crocus sativus L.) using LC-MS in the positive mode.

\begin{tabular}{|c|c|c|c|c|}
\hline Peak no. & Compound identification & $t_{\mathrm{R}}(\min )$ & {$[\mathrm{M}+1](\mathrm{m} / z)$} & Ref. \\
\hline 1 & Cinnamyl isovalerate & 35.0 & 219.12 & [79] \\
\hline 2 & Crocin E & 36.0 & 491.7 & [78] \\
\hline 3 & Crocetin & 44.1 & 329.4 & [78] \\
\hline 4 & Isorhamnetin-3-O- $\beta$-D-glucopyranoside & 38.0 & 479.7 & [78] \\
\hline 5 & Kaempferol 3-sophoroside-7-glucoside & 42.8 & 772.2 & [79] \\
\hline 6 & Crocusatin & 9.6 & 185.4 & {$[80]$} \\
\hline 7 & Taxifolin 7-O-hexoside & 24.2 & 466.3 & {$[80]$} \\
\hline 8 & Kaempferol 3-O-hexoside-7-O-(acetyl)-hexoside & 25.7 & 653.1 & {$[80]$} \\
\hline 9 & Sinapic acid & 32.8 & 224.8 & {$[80]$} \\
\hline 10 & Adenosine & 38.0 & 268.0 & {$[80]$} \\
\hline 11 & Tamarixetin 3-O-bihexoside & 36.2 & 641.1 & {$[80]$} \\
\hline 12 & Rhamnetin & 30.8 & 317.1 & [79] \\
\hline 13 & Naringenin & 33.3 & 273.3 & [79] \\
\hline 14 & Tamarixetin O-kaempferol biflavonoid hexoside & 23.1 & 747.1 & {$[78,80]$} \\
\hline 15 & Karatavigenin B & 24.3 & 569.3 & {$[79]$} \\
\hline 16 & Anhalonidine & 28.0 & 224.1 & [79] \\
\hline 17 & Baicalein & 30.9 & 271.2 & [79] \\
\hline 18 & 4,6,8-Megastigmatriene & 31.7 & 177.7 & [79] \\
\hline
\end{tabular}

Additionally, according to the manufacturer's instruction, the levels of tPA, which digests fibrin substrates, and PAI were also evaluated in peritoneal lavage fluid by ELISA kits. Subsequently, the tPA/PAI ratio was calculated by dividing the level of tPA by PAI level. The levels of cytokines were reported as $\mathrm{pg} / \mathrm{mg}$ protein.

\subsection{In Vitro Study}

2.5.1. Cell Culture Condition. Murine macrophage cell line, RAW 264.7, was purchased from Pasture Institute, Tehran,
Iran. The cells were cultured in DMEM/F12 enriched with $10 \% v / v$ foetal bovine serum (FBS), $100 \mathrm{IU} / \mathrm{ml}$ penicillin, and $100 \mu \mathrm{g} / \mathrm{ml}$ streptomycin at $37^{\circ} \mathrm{C}$ in a humidified atmosphere with $5 \% v / v \mathrm{CO}_{2}[40]$.

2.5.2. Proliferation Assay. To investigate that C. sativus extract had no cytotoxicity and inhibitory effects on RAW 264.7 cells, the cells were cultured at a density of $3 \times 10^{3}$ cells/well in 96-flat well plates and incubated overnight [40]. Thereafter, the cells were incubated with different 


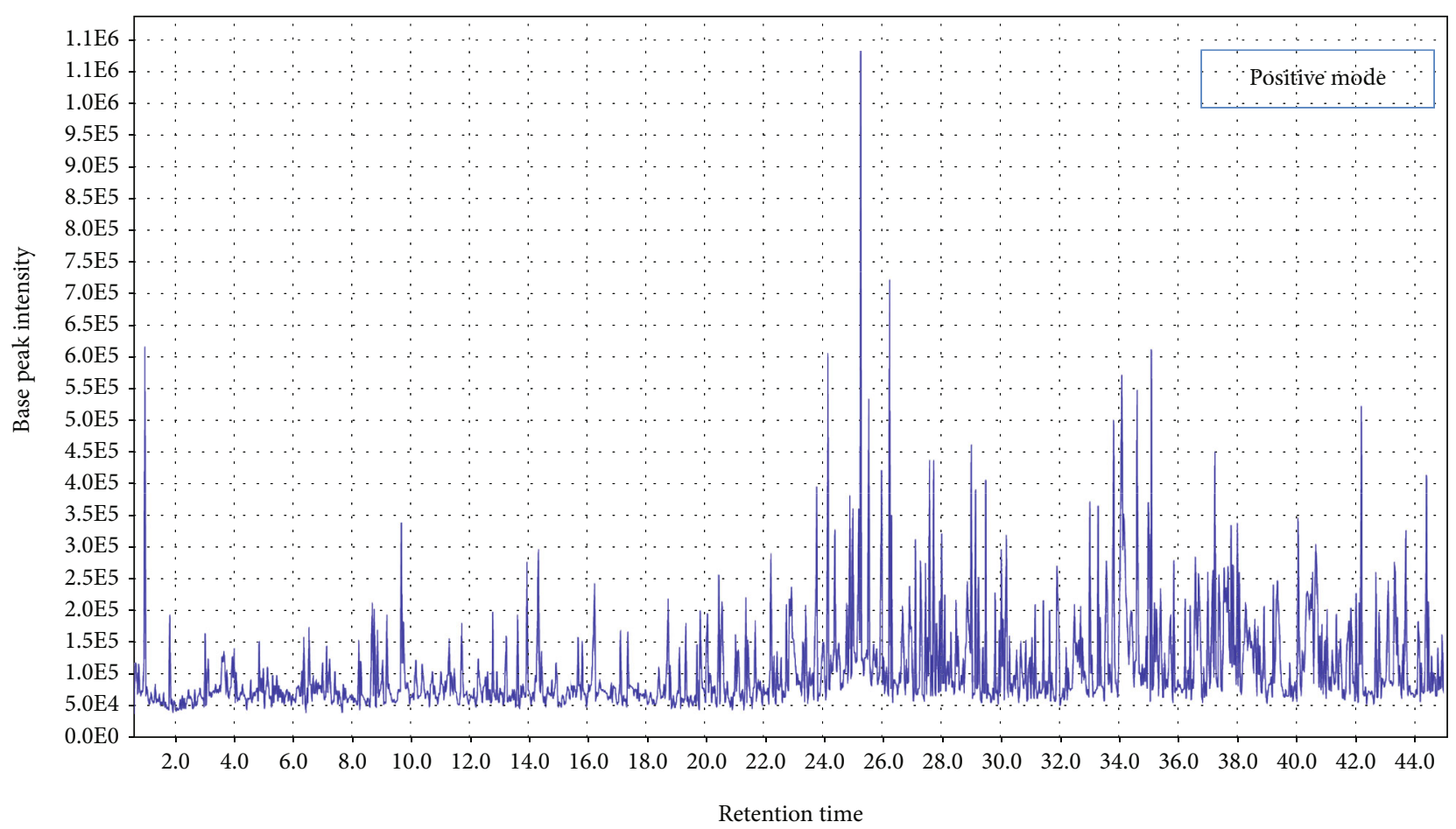

(a)

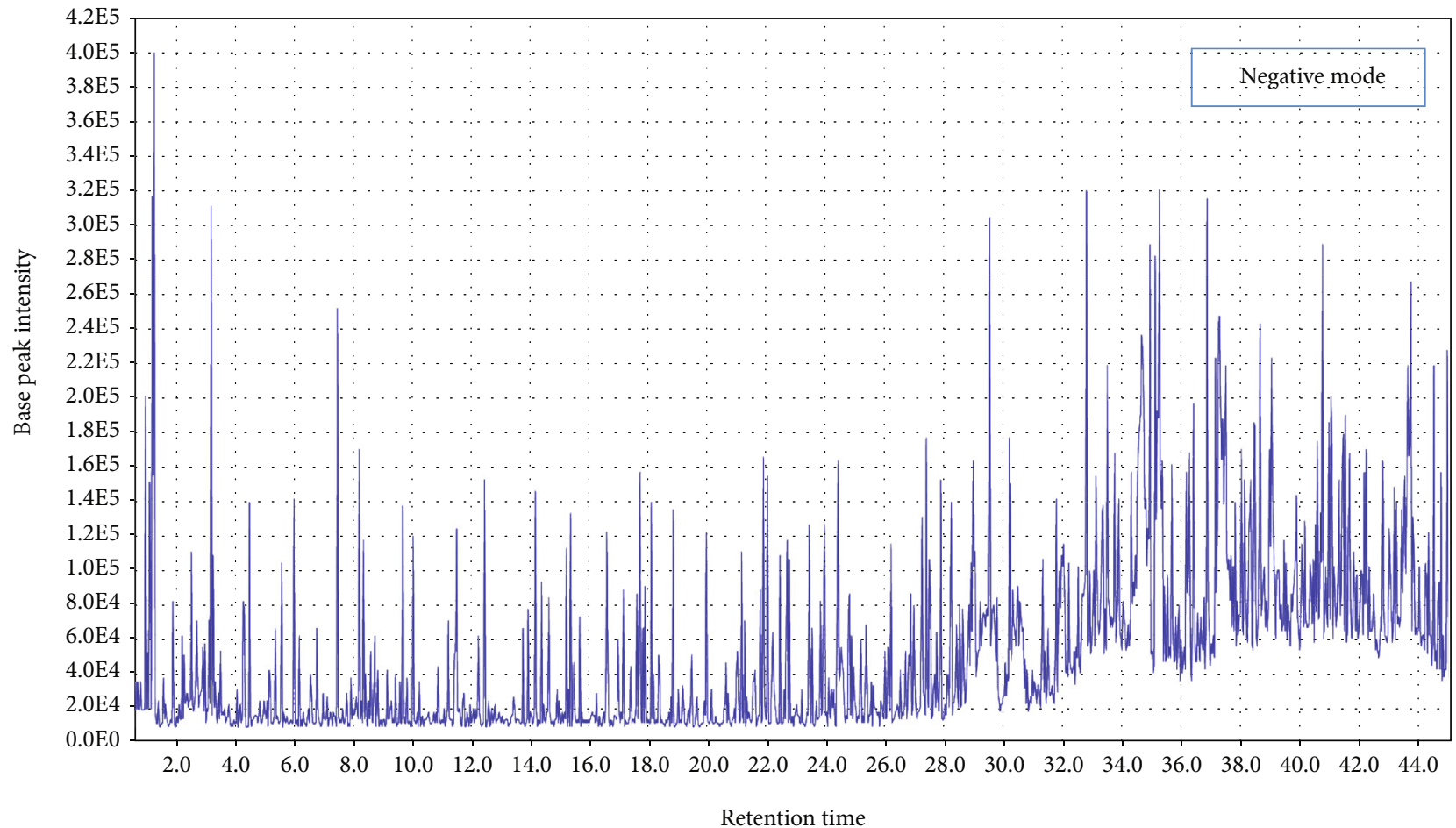

(b)

FIgURe 1: Continued. 


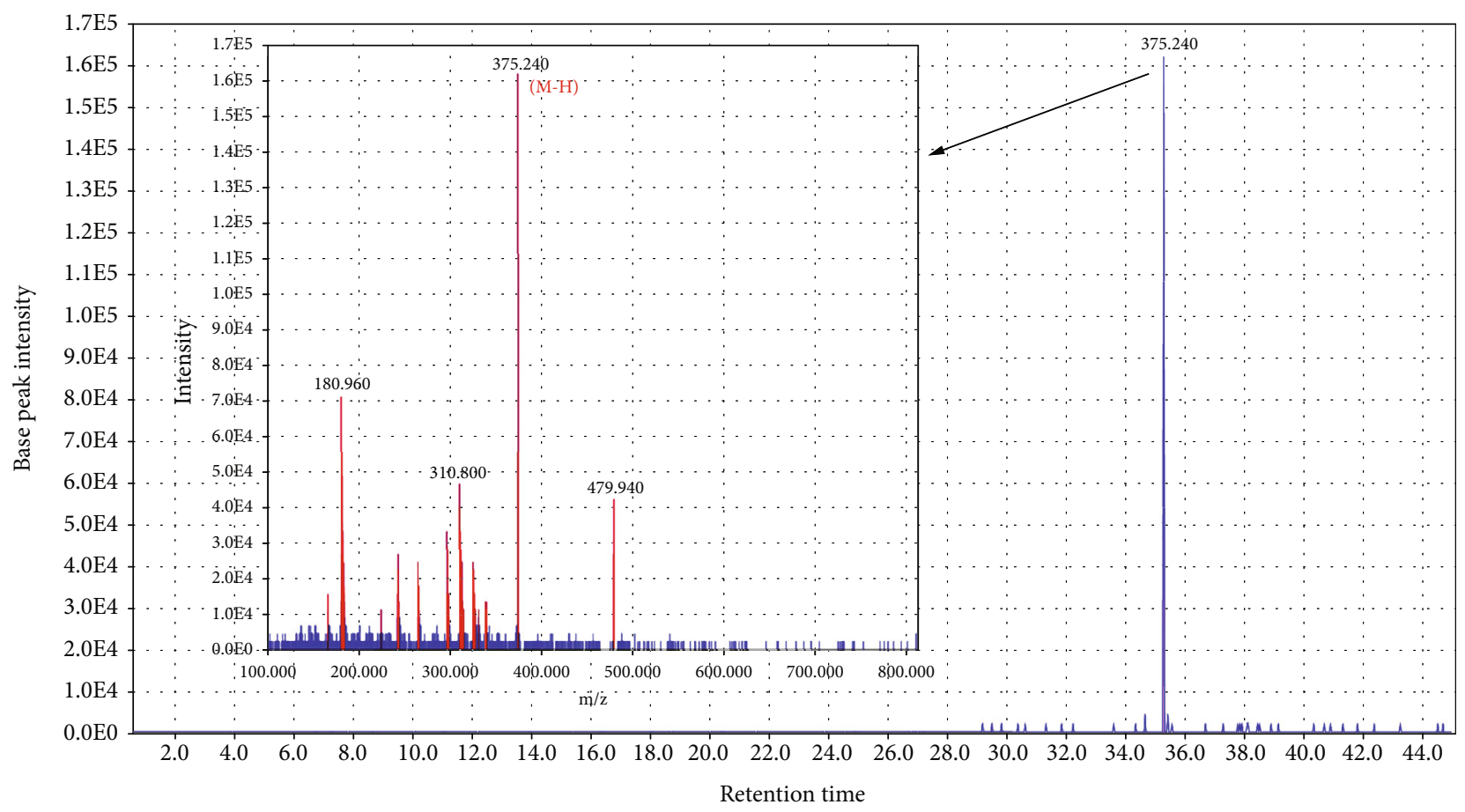

(c)

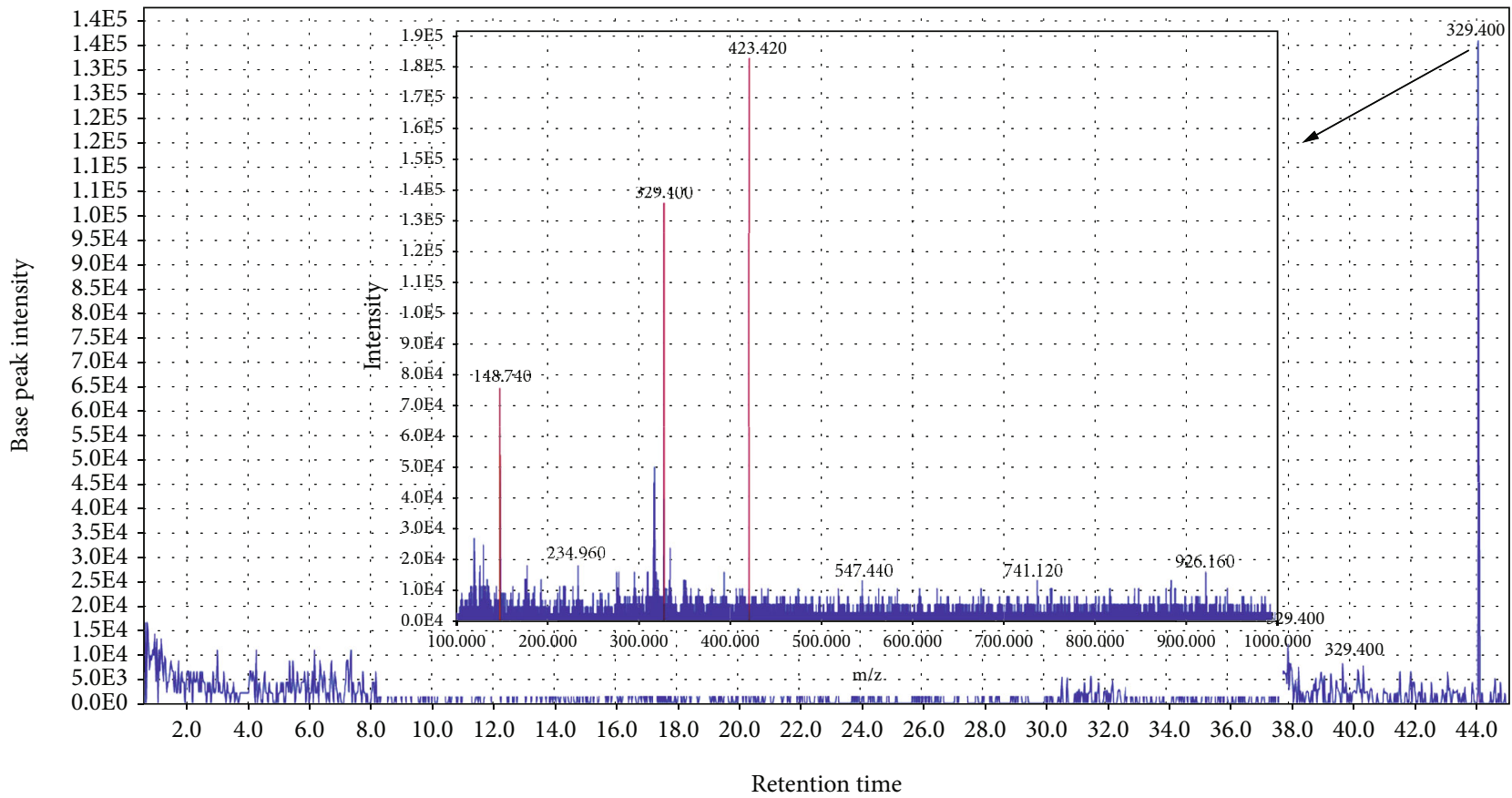

(d)

Figure 1: Continued. 


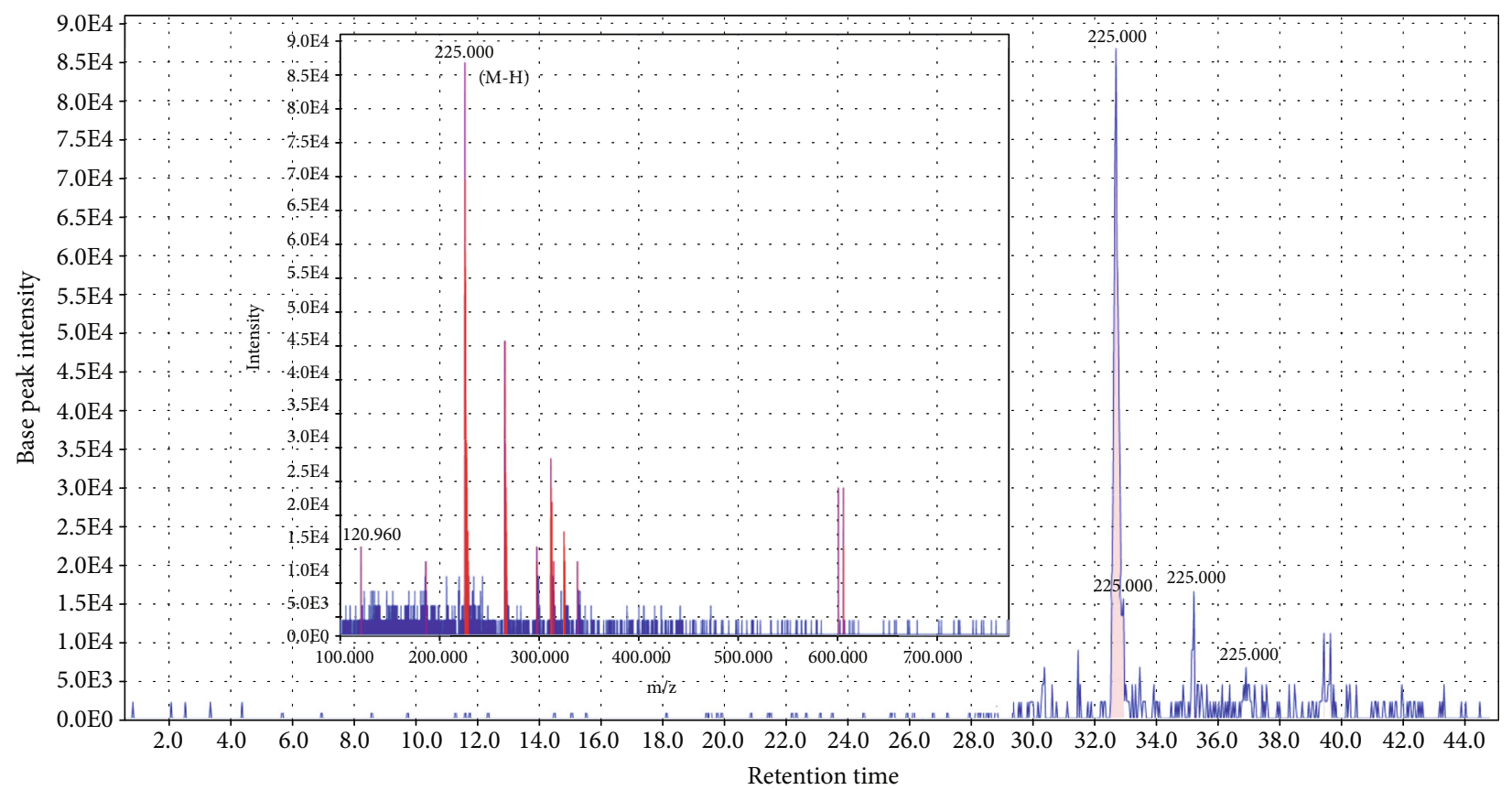

(e)

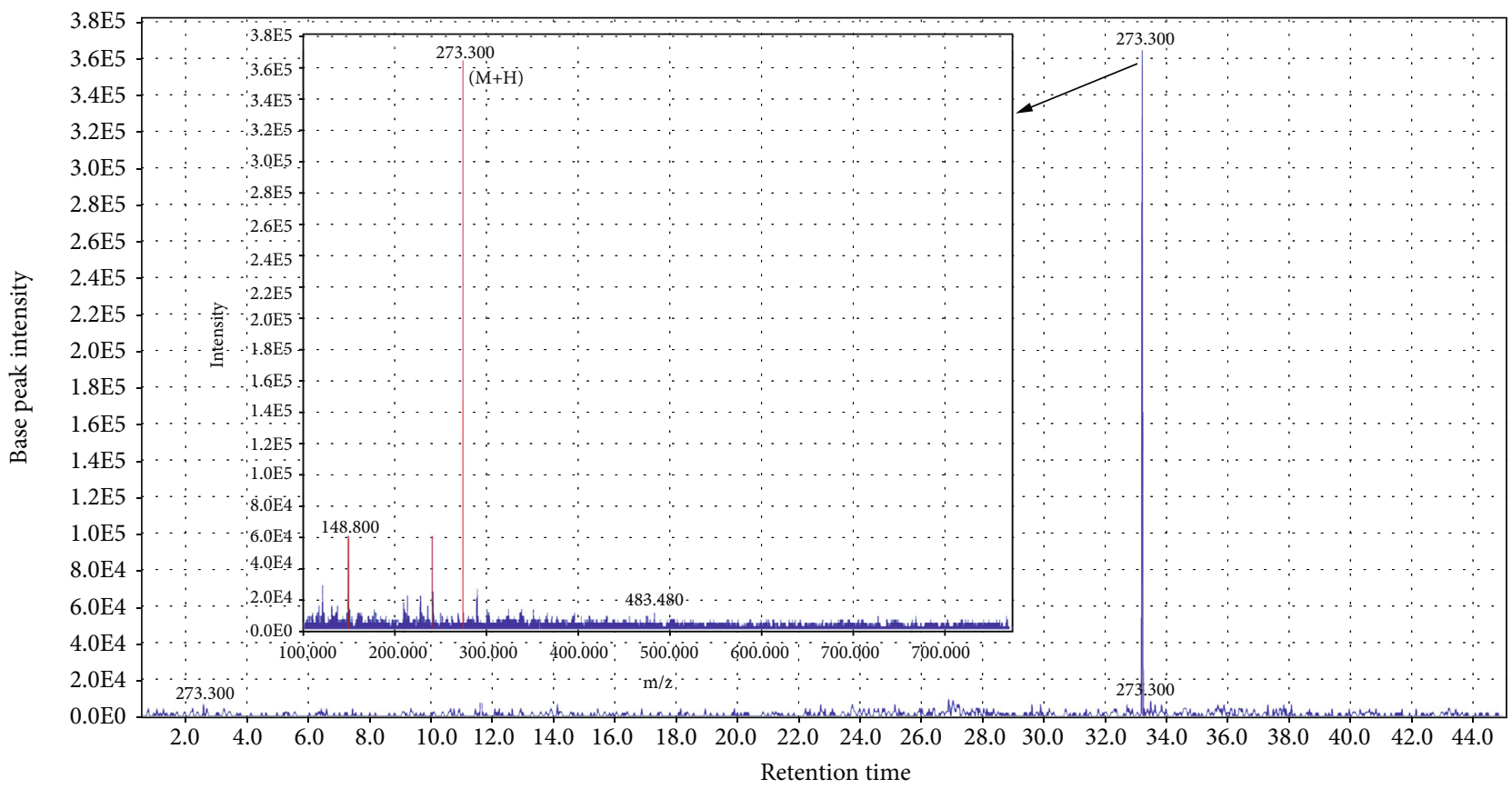

(f)

FIgURe 1: Continued. 


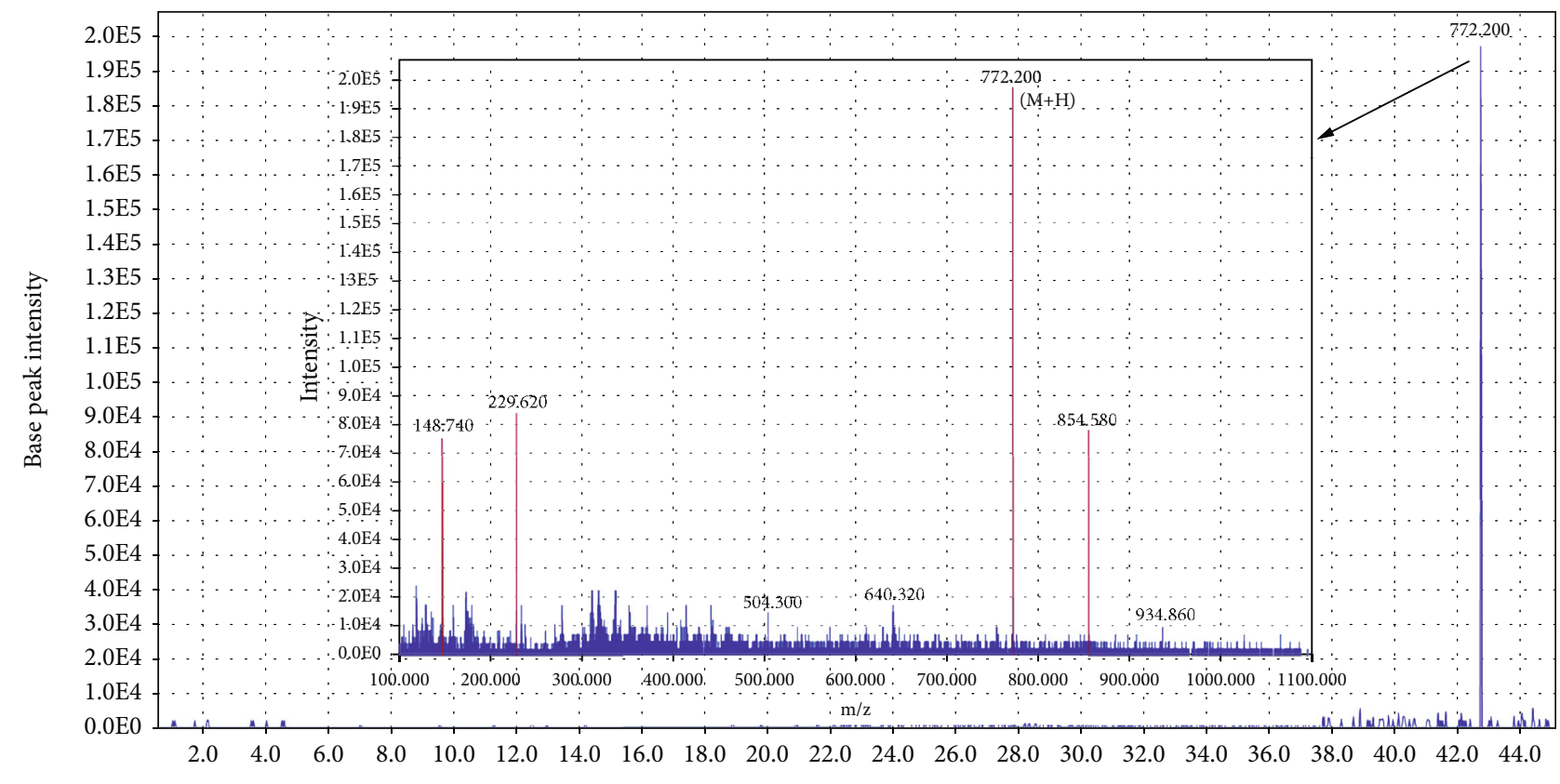

Retention time

(g)

Figure 1: (a) The total ion chromatogram of C. sativus (Crocus sativus L.) using LC-MS in the positive mode. (b) The total ion chromatogram of C. sativus (Crocus sativus L.) using LC-MS in the negative mode. (c) Chromatogram of 4-( $\alpha$-D-glucopyranosyl)-2, 6,6trimethyl-1-cyclohexene-1-carboxaldehyde (picrocrocin), and corresponding mass adduct, [M-H], at $m / z$ 375.2. (d) Chromatogram of dihydrojasmonic acid, methyl ester, and corresponding mass adduct, [M-H], at $m / z 225.0$. (e) Chromatogram of dihydrojasmonic acid, methyl ester and corresponding mass adduct, $[\mathrm{M}-\mathrm{H}]$, at $m / z$ 225.0. (f) Chromatogram of naringenin and corresponding mass adduct, [M $+\mathrm{H}$ ], at $\mathrm{m} / \mathrm{z}$ 273.3. (g) Chromatogram of Kaempferol 3-sophoroside-7-glucoside and corresponding mass adduct, [M+H], at $m / z 772.2$.

concentrations of $C$. sativus extract $(100,200$, and $400 \mu \mathrm{g} / \mathrm{ml}$, according to the preliminary evaluation), PFD $(100 \mu \mathrm{g} / \mathrm{ml}$, as a positive control group, [41]), or vehicle (contained $0.1 \%$ dimethyl sulfoxide, DMSO) for $48 \mathrm{~h}$, at $37^{\circ} \mathrm{C}$ and $5 \% \mathrm{v} / \mathrm{v}$ $\mathrm{CO}_{2}$.

In another set of experiments, we assessed the effects of different concentrations of $C$. sativus extract (100, 200, and $400 \mu \mathrm{g} / \mathrm{ml}$, according to the preliminary evaluation), PFD $(100 \mu \mathrm{g} / \mathrm{ml}$, as a positive control group, [41]), or vehicle (contained $0.1 \%$ dimethyl sulfoxide, DMSO) in the presence of recombinant mouse TGF- $\beta 1$ stimulation $(20 \mathrm{ng} / \mathrm{ml}$ [42]) on cell proliferation. In this regard, the cells $\left(3 \times 10^{3}\right)$ were incubated with the extract, $\mathrm{PFD}$, vehicle, or medium for $24 \mathrm{~h}$ and then coincubated with TGF- $\beta 1(20 \mathrm{ng} / \mathrm{ml} \mathrm{[42])}$ for another $24 \mathrm{~h}$, at $37^{\circ} \mathrm{C}$ and $5 \% v / v \mathrm{CO}_{2}$. Afterwards, cell proliferation was also assessed by the MTT method.

Finally, cell proliferation was assessed using the 3-(4,5dimethylthiazol-2-yl)-2,5-diphenyl-2H-tetrazolium bromide (MTT) method. Briefly, $10 \mu \mathrm{l}$ of MTT solution with a final concentration of $5 \mathrm{mg} / \mathrm{ml}$ was appended to each well to be incubated for $3 \mathrm{~h}$. After discarding the medium culture (DMEM/F12), $100 \mu \mathrm{l}$ of DMSO was used to dissolve the formed formazan crystals. The absorption of the 96-flat wells plate was recorded by ELISA reader (Awareness Inc., USA) at $570 \mathrm{~nm}$ and $620 \mathrm{~nm}[40,43]$.

2.5.3. Assessment of Secretory Cytokines Levels and Intracellular Levels of iNOS and Arg-1. According to the manufacturer's instructions, the anti-inflammatory (IL-10) levels and inflammatory cytokine (TNF- $\alpha$ ) and angiogenesis factor (VEGF) were measured by the ELISA-based method. The cells were cultured in 6 -well plates $\left(2 \times 10^{6}\right.$ cells/each well) and incubated with different concentrations of $C$. sativus extract $(100,200$, and $400 \mu \mathrm{g} / \mathrm{ml}$, according to the preliminary evaluation), PFD $(100 \mu \mathrm{g} / \mathrm{ml}$, as a positive control group, [41]), or vehicle (contained $0.1 \%$ dimethyl sulfoxide, DMSO) in the presence of recombinant mouse TGF- $\beta 1$ stimulation (20 ng/ml, providing M2 phenotype cells [42]) for $24 \mathrm{~h}$ and then coincubated with TGF- $\beta 1(20 \mathrm{ng} / \mathrm{ml}$ [42]) for another $24 \mathrm{~h}$, at $37^{\circ} \mathrm{C}$ in a $5 \% v / v \mathrm{CO}_{2}$ incubator. Finally, the supernatants were collected to measure the levels of cytokines. The levels of cytokines were reported as $\mathrm{pg} / \mathrm{mg}$ protein. Moreover, the cells were collected and lysed using a lysis buffer and then homogenised (DIAX 100, Heidolph, Schwabach, Germany) on the cold water $\left(0-4^{\circ} \mathrm{C}\right)$ for $2-$ $3 \mathrm{~min}$ along with vortexing (every $30 \mathrm{sec}$ ). The samples were centrifuged at $12,000 \mathrm{~g}$ for $10 \mathrm{~min}$ at $4^{\circ} \mathrm{C}$, and $50 \mu \mathrm{l}$ of supernatants had then undergone an assessment. The levels of iNOS and Arg-1 were reported as $\mathrm{ng} / \mathrm{mg}$ protein.

2.6. Statistical Analysis. Data were analysed using GraphPad Prism (version 6.01) software and presented according to the nature of parametric or nonparametric as the means \pm SEM or median \pm interquartile range, respectively. $P$ values $\leq 0.001,0.01$, and 0.05 were statistically considered significant. For parametric data, one-way ANOVA was performed 


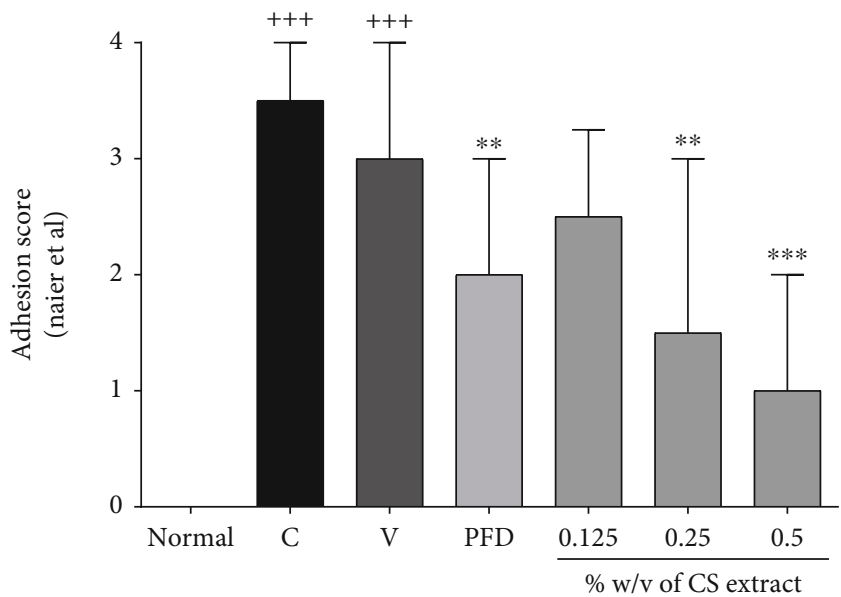

(a)

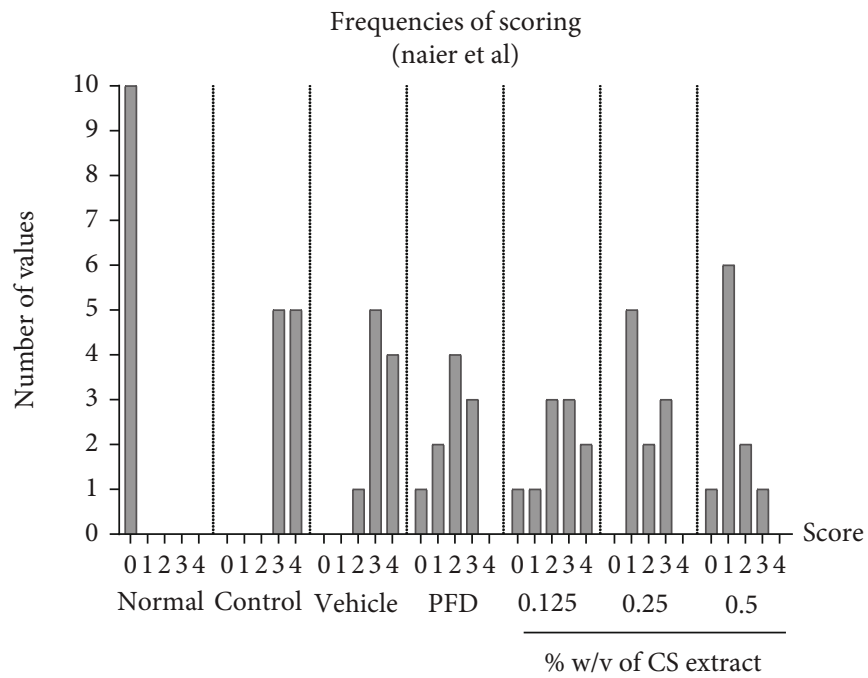

(b)

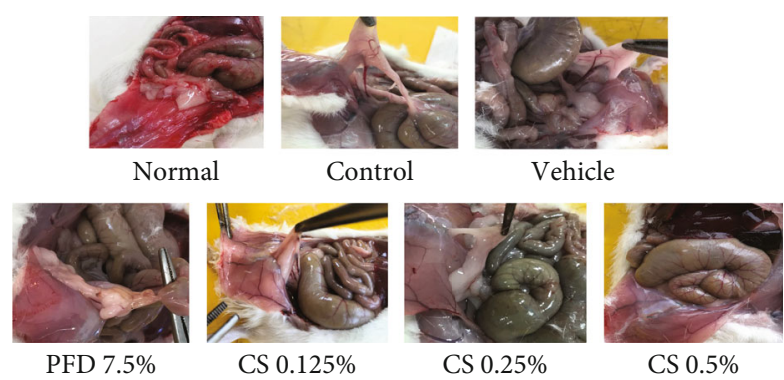

(c)

Figure 2: Continued. 


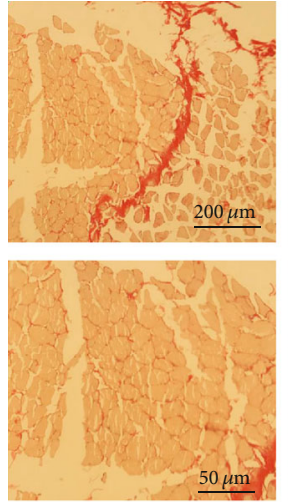

Normal
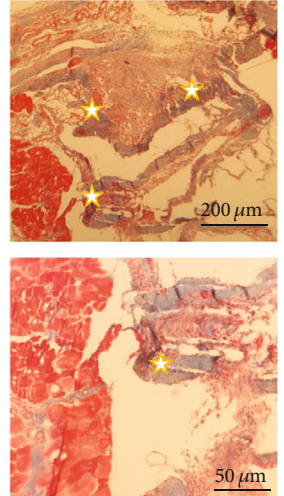

Vehicle
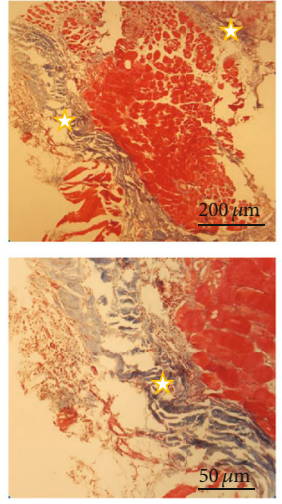

Control
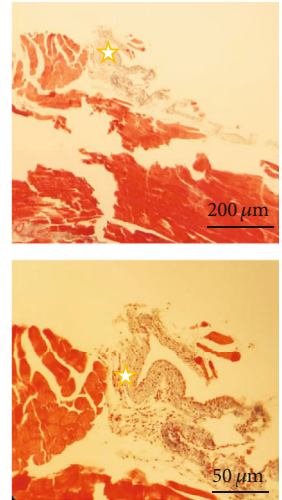

PFD
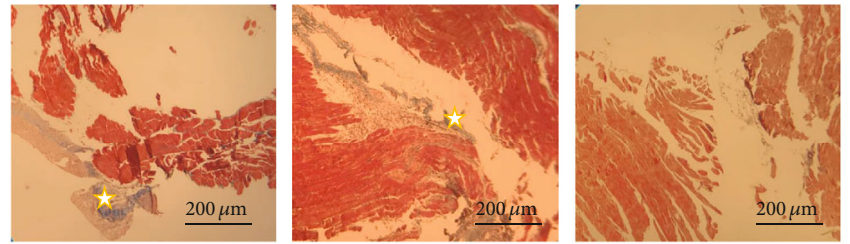

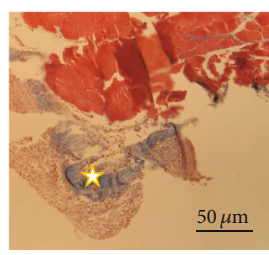

$0.125 \% \mathrm{w} / \mathrm{v}$

CS extract

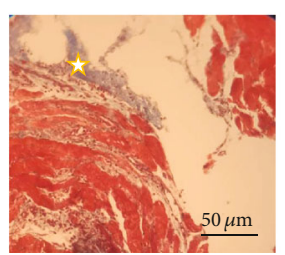

$0.25 \% \mathrm{w} / \mathrm{v}$

CS extract

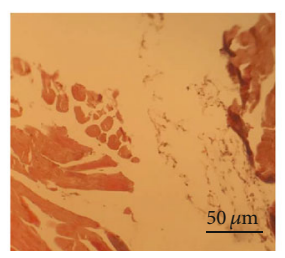

$0.5 \% \mathrm{w} / \mathrm{v}$

CS Extract

(d)

Figure 2: The effects of different concentrations of $C$. sativus $(0.125,0.25$, and $0.5 \% w / v)$ and PFD $(7.5 \% w / v)$ on adhesion score (a) and frequencies of scoring (b) following postoperational-induced peritoneal adhesion. (c) The images of adhesion bands in different groups. (d) The effects of different doses of C. sativus extract on adhesion formation and collagen deposition by histopathological evaluation using Masson's trichrome staining; blue colour intensities (marked with white stars) represent fibrosis and collagen deposition. Data were presented as the median \pm interquartile range (IQR) $(n=10) .{ }^{* * *} P<0.001$ and ${ }^{* *} P<0.01$ compared to the control group.

with the following Tukey's Kramer post hoc test. However, for nonparametric data (adhesion score), the KruskalWallis test was done following Dunn's multiple comparisons posttest. The data and statistical analysis comply with the recommendations on experimental design, analysis [44], and data sharing and preclinical pharmacology presentation $[45,46]$.

\section{Results}

3.1. LC-MS Analysis and Characterisation of C. sativus $L$. Extract. Collectively, 35 compounds (in ESI+ and ESI-) were identified in the hydroethanolic extract of $C$. sativus L., including flavonoids and crocins (crocin and its derivatives). Data concerning the identification of the compounds are shown in Tables 2 and 3. The total ion chromatograms of C. sativus L. extract in both ESI+ and ESI- modes are shown in Figures 1(a) and 1(b), respectively. The MS spectral data were compared with the reported compounds in some previous literature. Figures 1(a)-1(f) are examples of extracted ion chromatograms from the total ion chromatogram and its related mass. Some flavonoids, including quercetin 3-oru- tinosylrhamnoside, quercetin 3-O-rutinoside, Kaempferol 3glucoside, tamarixetin 3-O-bihexoside, rhamnetin, and naringenin, were detected in C. sativus L. extract. Apocarotenoids, including crocin, crocetin, and their derivatives, apart from imparting colours to $C$. sativus, also have antioxidant properties (40).

\subsection{In Vivo Results}

3.2.1. The Effect of C. sativus and PFD on Adhesion Score. The adhesion scores in both the control and vehicle groups were increased compared to those in the normal group $(P<0.001$ for both cases, Figures $2(\mathrm{a})-2(\mathrm{c}))$. Treatment with PFD $(7.5 \% w / v, P<0.01)$ and $C$. sativus $(0.25 \% w / v, P<$ 0.01 , and $0.5 \% w / v, P<0.001)$ significantly attenuated the levels of adhesion score compared to the control group (Figure 2(a)). The frequencies of adhesion score are indicated in Figure 2(b) according to the Nair et al. scoring system. Figure 2(c) shows the samples of the adhesion band in each group.

3.2.2. The Effects of PO Extract on Histopathological Alteration of Peritoneal Fibrosis. Our histopathological 


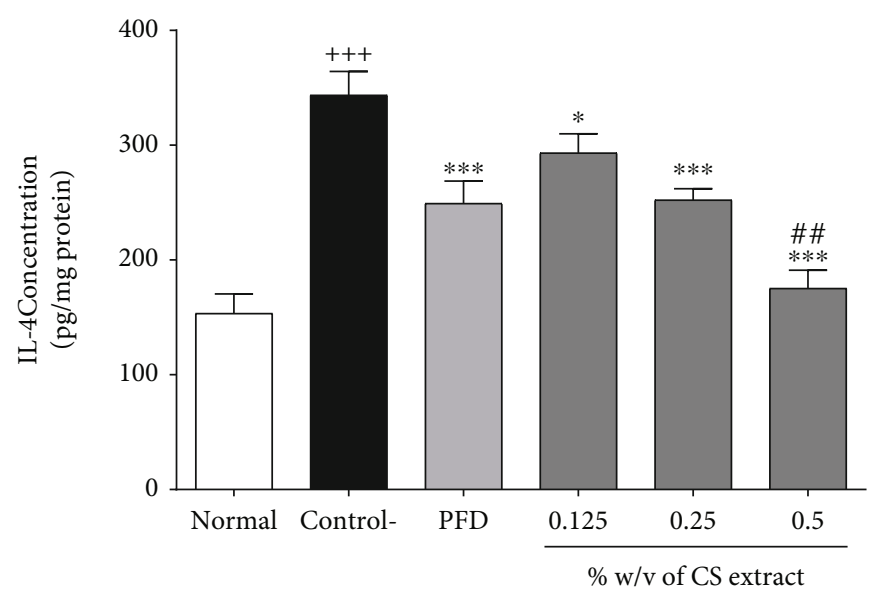

(a)

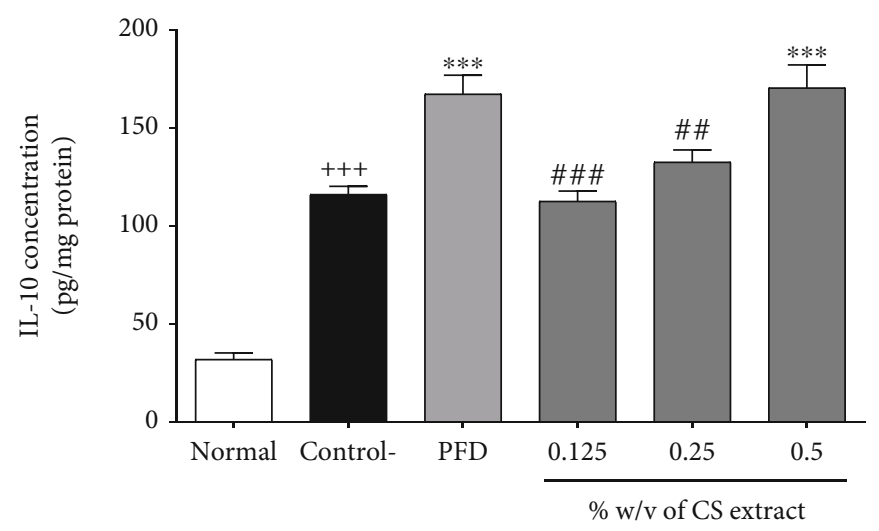

(b)

FIGURE 3: The effect of different concentrations of C. sativus $(0.125,0.25$, and $0.5 \% w / v)$ and PFD (7.5\% $w / v)$ on IL-4 (a) and IL-10 (b) levels following the postoperational-induced peritoneal adhesion. Data were presented as the mean $\pm \operatorname{SEM}(n=8)$. ${ }^{+++} P<0.001$ compared to the normal group, ${ }^{* * *} P<0.001$ compared to the control group, and ${ }^{\# \#} P<0.001$ and ${ }^{\# \#} P<0.01$ compared to the PFD group. The lines represent a significant difference between the three C. sativus groups.

results showed the levels of tissue fibrosis and collagen deposition (blue colour) in both the vehicle and control groups (Figure 2(d)). On the contrary, the blue colour's intensities were notably lower in all doses of the extract groups and PFD as a positive control than the control group (Figure 2(d)).

3.2.3. The Effect of C. sativus and PFD on Anti-Inflammatory Biomarkers. Following the peritoneal adhesion induction, the levels of IL-4 and IL-10 were markedly increased in the control group compared to the normal group $(P<0.001$ for both cases, Figures 3(a) and 3(b)). The level of IL-4 was notably diminished by treatment with either all concentrations of C. sativus $(0.125 \% w / v, P<0.05,0.25 \% w / v, P<$ 0.001 , and $0.5 \% w / v, P<0.001$, Figure $3(\mathrm{a}))$ or PFD $(7.5 \%$ $w / v, P<0.001$, Figure 3(a)) compared to the control group. The extract of C. sativus $(0.5 \% w / v, P<0.01$, Figure $3(\mathrm{a}))$ significantly reduced IL-4 level in peritoneal lavage fluid than that in the PFD-treated group $(7.5 \% w / v)$. Both PFD (7.5\% $w / v, P<0.001$, Figure 3(b)) and C. sativus (0.5\% $w / v$, $P<0.001$, Figure 3(b)) considerably increased the level of IL-10 in peritoneal lavage fluid.
3.2.4. The Effect of $C$. sativus and PFD on the Levels of $t P A$, $P A I$, and tPA/PAI Ratio. The levels of tPA $(P<0.05$, Figure $4(\mathrm{~b}))$ and tPA/PAI ratio $(P<0.001$, Figure $4(\mathrm{c}))$ were diminished, but PAI level $(P<0.001$, Figure $4(\mathrm{a}))$ was increased in the control group compared to the normal group. Treatment with C. sativus $(0.125 \% w / v, P<0.05$, $0.5 \% w / v, P<0.001$, and $0.25 \% w / v, P<0.001)$ and PFD $(7.5 \% w / v, P<0.001)$ significantly increased the tPA level in a concentration-dependent manner (Figure 4(b)). Treatment with a high concentration of C. sativus $(0.5 \% \mathrm{w} / \mathrm{v})$ and PFD $(7.5 \% \quad w / v)$ markedly decreased PAI level $(P<0.01$ for both cases, Figure $4(\mathrm{a}))$ and significantly increased tPA/PAI ratio $(P<0.001$ for both cases, Figure $4(\mathrm{c}))$ in the peritoneal lavage fluid compared to the control group.

3.2.5. The Effect of C. sativus and PFD on Fibrotic (TGF- $\beta 1$ ) and Angiogenesis (VEGF) Parameters. The levels of TGF- $\beta 1$ $(P<0.001$, Figure 5(a)) and VEGF $(P<0.001$, Figure 5(a) $)$ were significantly increased in the control group compared to the normal group. Two higher concentrations of $C$. sativus $(0.25 \% w / v, P<0.001$, and $0.5 \% w / v, P<0.001)$ 


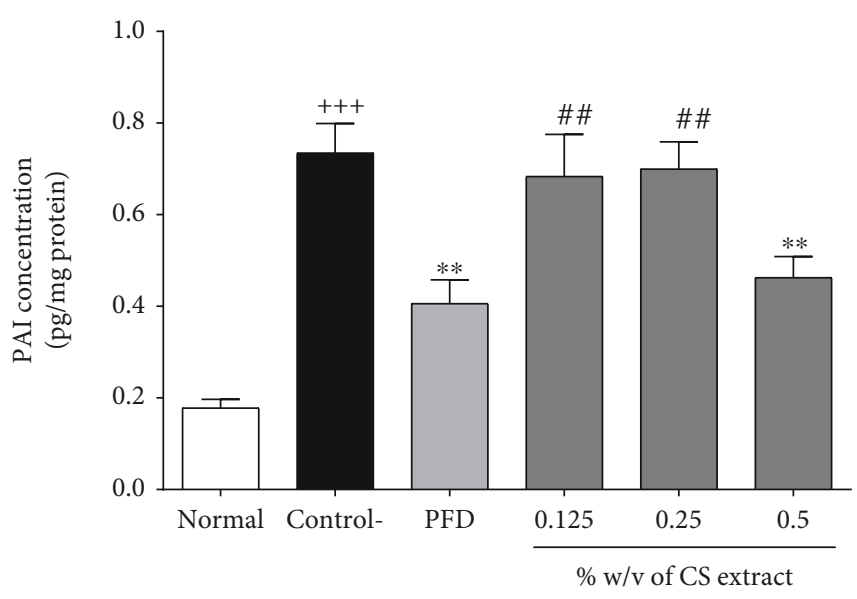

(a)

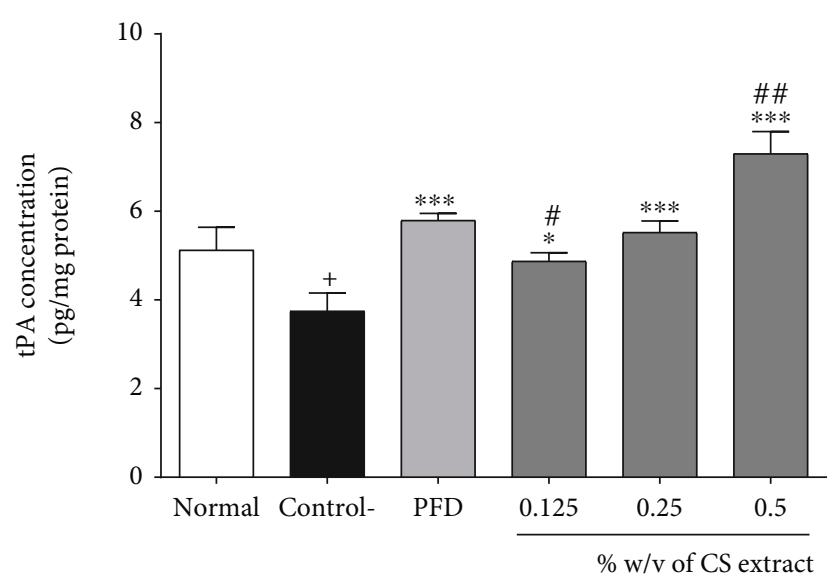

(b)

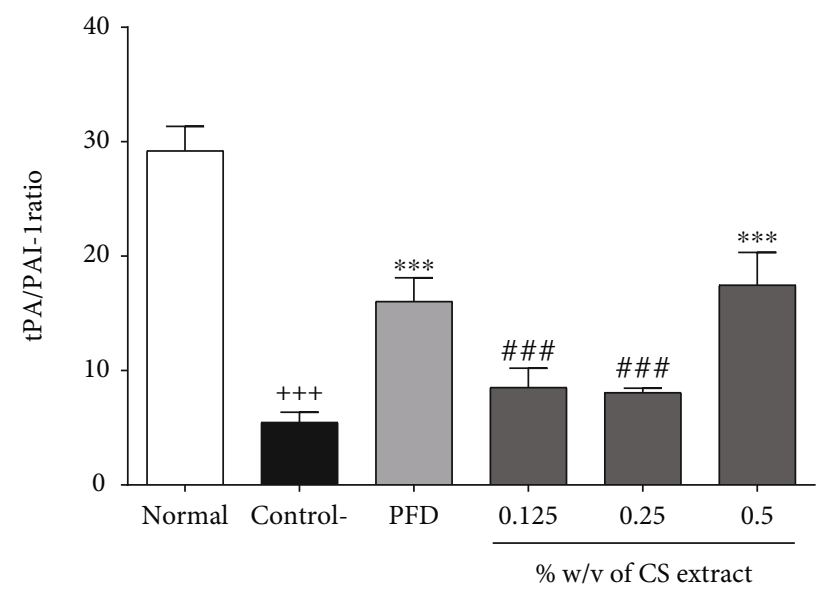

(c)

Figure 4: The effect of different concentrations of $C$. sativus $(0.125,0.25$, and $0.5 \% w / v)$ and PFD (7.5\% $w / v)$ on PIA (a), tPA (b), and tPA/ PAI ratio (c) levels following post-operational-induced peritoneal adhesion. Data were presented as the mean \pm SEM $(n=8) .{ }^{+++} P<0.001$ and $P<0.01$ compared to the normal group, ${ }^{* * *} P<0.001$ to ${ }^{*} P<0.05$ compared to the control group, and ${ }^{\# \# \#} P<0.001$ to ${ }^{\#} P<0.05$ compared to the PFD group. The lines represent a significant difference between the three C. sativus groups.

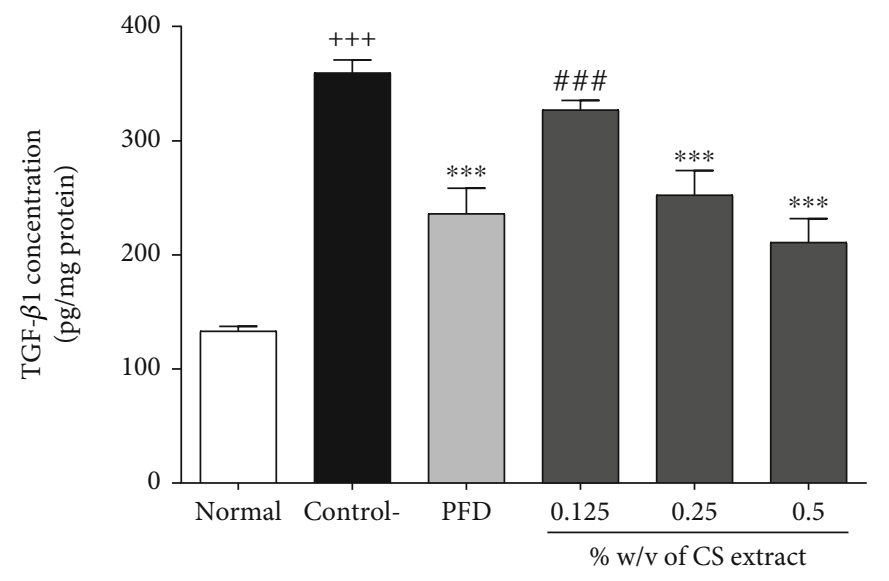

(a)

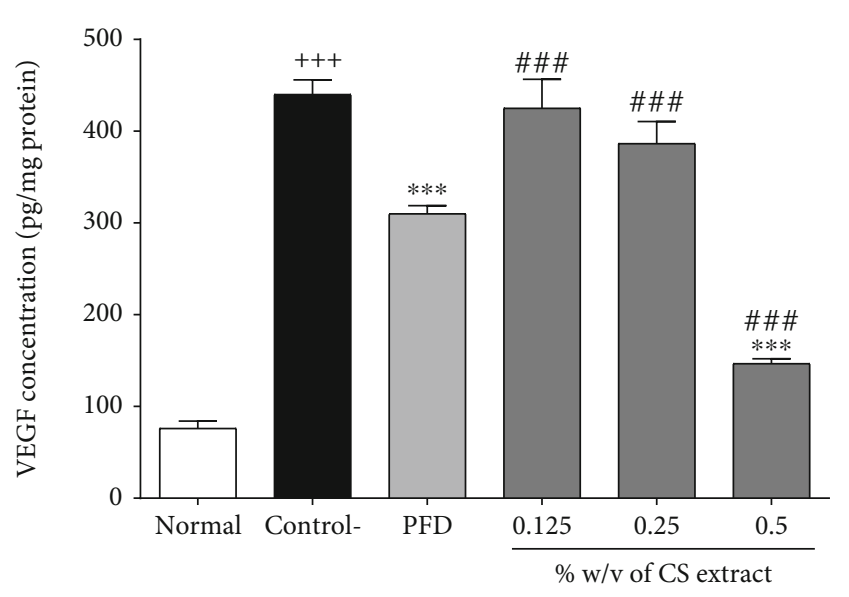

(b)

FIGURE 5: The effect of different concentrations of C. sativus $(0.125,0.25$, and $0.5 \% w / v)$ and PFD (7.5\% $w / v)$ on TGF- $\beta 1$ (a) and VEGF (b) levels following postoperational-induced peritoneal adhesion. Data were presented as the mean $\pm \operatorname{SEM}(n=8)$. ${ }^{+++} P<0.001$ compared to the normal group, ${ }^{* * *} P<0.001$ compared to the control group, and ${ }^{\# \# \#} P<0.001$ compared to the PFD group. The lines represent a significant difference between the three C. sativus groups. 


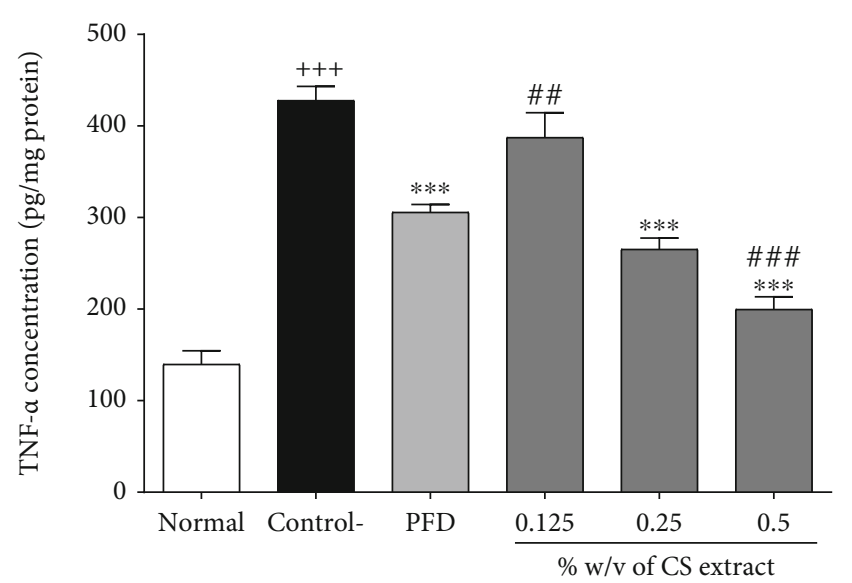

(a)

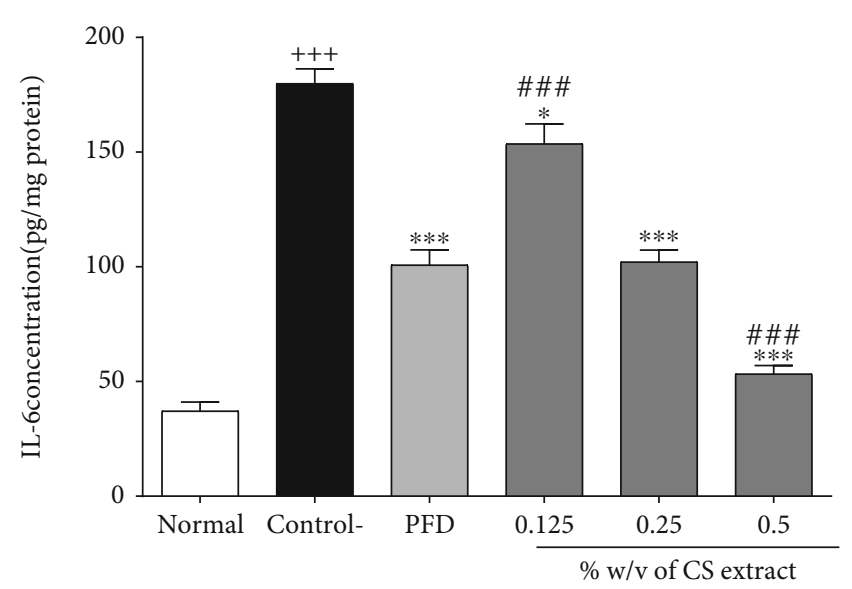

(b)

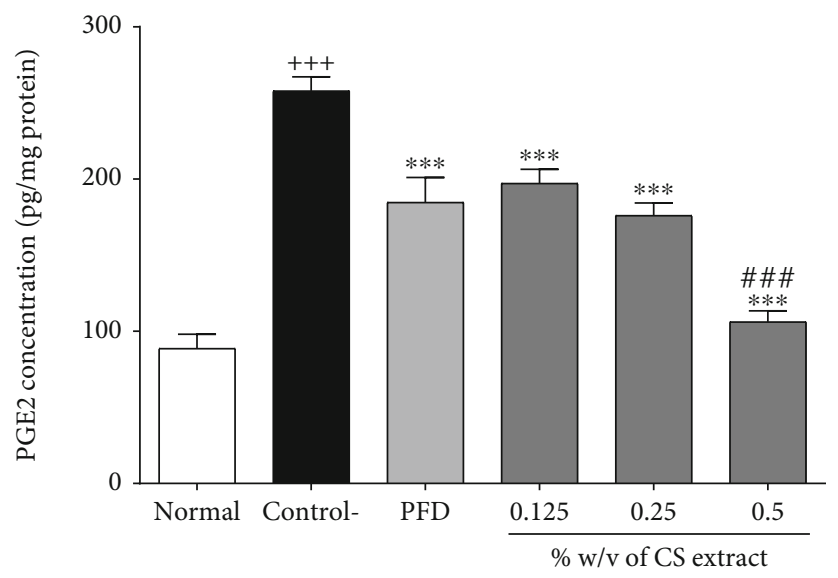

(c)

Figure 6: The effect of different concentrations of $C$. sativus $(0.125,0.25$, and $0.5 \% w / v)$ and PFD (7.5\% $w / v)$ on TNF- $\alpha$ (a), IL-6 (b), and $\mathrm{PGE}_{2}$ (c) levels following postoperational-induced peritoneal adhesion. Data were presented as the mean $\pm \mathrm{SEM}(n=8) .{ }^{+++} P<0.001$ compared to the normal group, ${ }^{* * *} P<0.001$ and $^{*} P<0.05$ compared to the control group, and ${ }^{\# \# \#} P<0.001$ and ${ }^{\# \#} P<0.01$ compared to the PFD group.

and PFD $(7.5 \% w / v, P<0.001)$ significantly reduced the concentration of TGF- $\beta 1$ compared to the control group (Figure 5(a)). However, the level of VEGF was significantly decreased by administration of either $C$. sativus $(0.5 \% \mathrm{w} / \mathrm{v}$, $P<0.001)$ or PFD $(7.5 \% w / v, P<0.001)$, compared to the control group (Figure 5(b)).

3.2.6. The Effect of $C$. sativus and PFD on Inflammatory Parameters (TNF- $\alpha, I L-6$, and $\left.P G E_{2}\right)$. All inflammatory parameters (TNF- $\alpha$, IL-6, and $\mathrm{PGE}_{2}$ ) were increased in the control group compared to the normal group $(P<0.001$ for all cases, Figures 6(a)-6(c)). All three concentrations of C. sativus $(0.125,0.25$, and $0.5 \% w / v)$ and $\mathrm{PFD}(7.5 \% w / v)$ decreased IL-6 $(P<0.001-0.05$ for all cases, Figure 6(b)) and $\mathrm{PGE}_{2}(P<0.001$ for all cases, Figure 6(c) $)$ levels. Moreover, $C$. sativus $(0.25,0.5 \% w / v)$ and PFD were diminished TNF- $\alpha$ concentration compared to the control group in peritoneal lavage fluid $(P<0.001$ for all cases, Figure 6(c)).

3.2.7. The Effect of $C$. sativus and PFD on MDA and GSH. The concentrations of MDA $(P<0.001$, Figure $7(\mathrm{a}))$ and
GSH $(P<0.001$, Figure $7(b))$ were significantly increased and decreased in the control group compared to the normal group, respectively. The levels of MDA and GSH, respectively, diminished and increased following treatment with C. sativus $(0.25,0.5 \% w / v)$ and $\operatorname{PFD}(7.5 \% w / v)$ in comparison to the control group in peritoneal lavage fluid $(P<0.001$ for all cases, Figures $7(a)$ and $7(b))$.

\subsection{In Vitro Results}

3.3.1. The Effect of C. sativus Extract and PFD on Cell Proliferation. In the absence of TGF- $\beta_{1}$ stimulation, no significant changes were found in cell proliferation between the groups treated with vehicle, C. sativus extract (100, 200 , and $400 \mu \mathrm{g} / \mathrm{ml})$ and PFD $(100 \mu \mathrm{g} / \mathrm{ml})$ and the control group (Figure $8(\mathrm{a})$ ). In the presence of TGF- $\beta_{1}$ stimulation $(20 \mathrm{ng} / \mathrm{ml})$, the levels of cell proliferation were significantly increased in both vehicle-treated and TGF- $\beta_{1}$ groups compared to the respected control group $(P<0.001$ for both cases, Figure $8(\mathrm{~b}))$. Pretreatment with $C$. sativus extract $(200$ and $400 \mu \mathrm{g} / \mathrm{ml})$ and PFD $(100 \mu \mathrm{g} / \mathrm{ml})$ significantly 


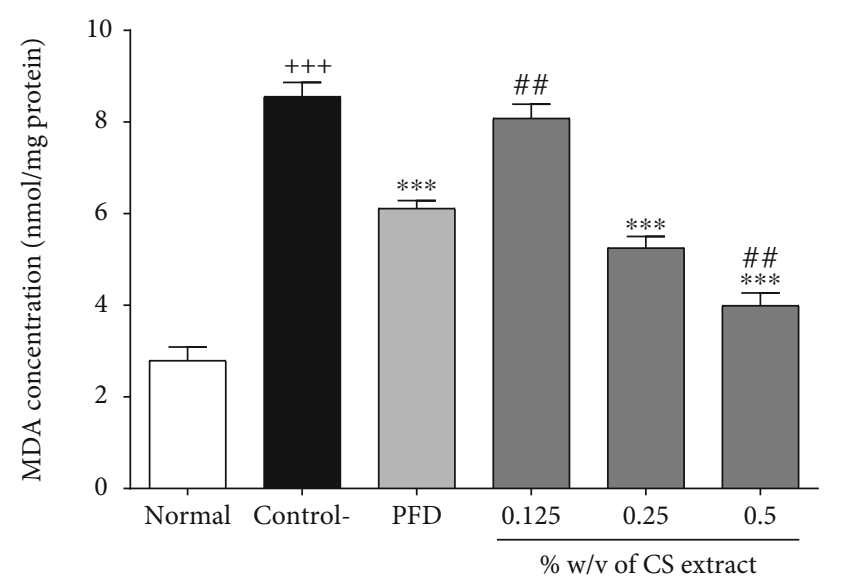

(a)

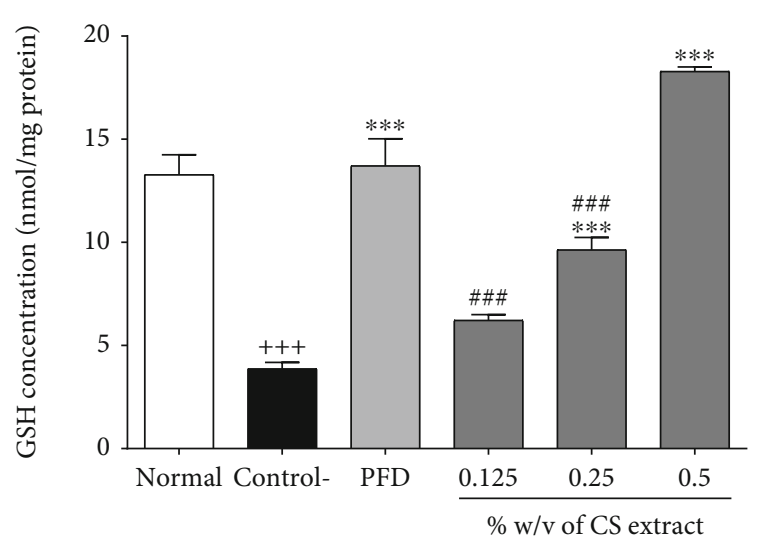

(b)

Figure 7: The effect of different concentrations of C. sativus $(0.125,0.25$, and $0.5 \% w / v)$ and PFD (7.5\% $w / v)$ on MDA (a) and GSH (b) levels following postoperational-induced peritoneal adhesion. Data were presented as the mean $\pm \operatorname{SEM}(n=8) .{ }^{+++} P<0.001$ and ${ }^{+} P<0.05$

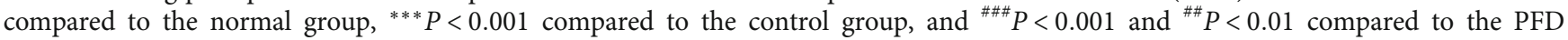
group. The lines represent a significant difference between the three C. sativus groups. The lines represent a significant difference between the two groups shown.

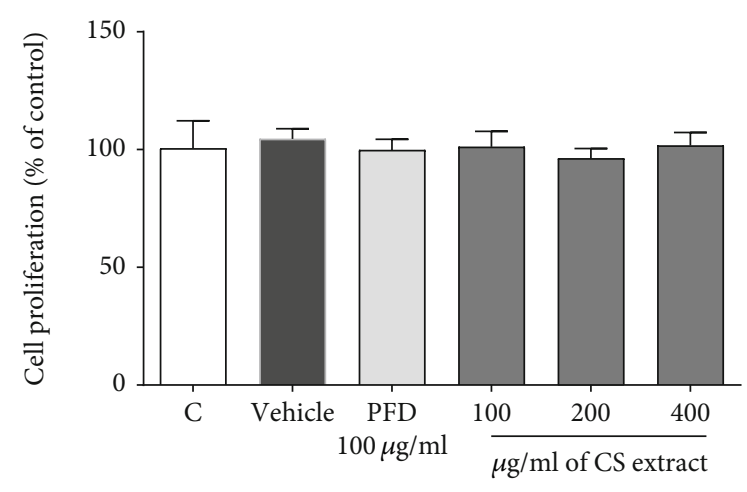

(a)

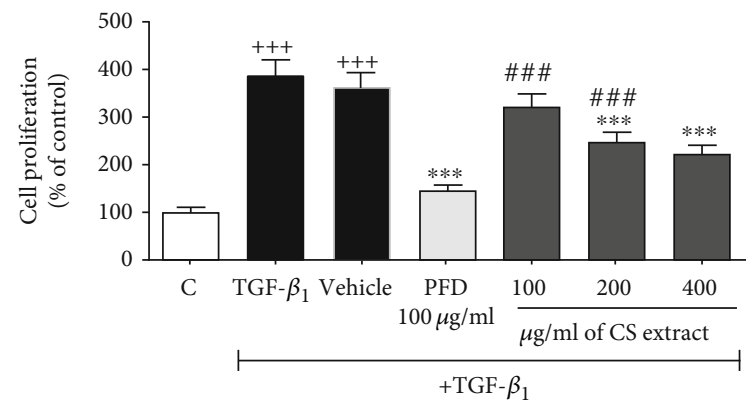

(b)

Figure 8: The effects of $C$. sativus extract $(100,200$, and $400 \mu \mathrm{g} / \mathrm{ml})$ and PFD $(100 \mu \mathrm{g} / \mathrm{ml})$ on proliferation level of RAW $264.7 \mathrm{macrophage}$ cells. Cell proliferation without stimulation (a) and cell proliferation with TGF- $\beta$ stimulation $(20 \mathrm{ng} / \mathrm{ml})(\mathrm{b})$. Data were presented as the mean \pm SEM $(n=6) .{ }^{+++} P<0.001$, compared with the control group; ${ }^{* * *} P<0.001$, compared with the TGF- $\beta_{1}$ group; ${ }^{\# \# \#} P<0.001$, compared with PFD group. The lines represent a significant difference between the two groups shown.

decreased the level of cell proliferation compared to the TGF- $\beta 1$-treated alone group $(P<0.001$ for all cases, Figure $8(\mathrm{~b}))$. The potential protective effects of $C$. sativus extract $(100$ and $200 \mu \mathrm{g} / \mathrm{ml})$ were lower than those of PFD $(100 \mu \mathrm{g} / \mathrm{ml})$ on decreasing the TGF- $\beta_{1}$-induced cell hyperproliferation $(P<0.001$ for both case, Figure $8(\mathrm{~b}))$.

3.3.2. The Effect of C. sativus Extract and PFD on TNF- $\alpha$, IL10 , and VEGF. In the presence of TGF- $\beta_{1}$ stimulation $(20 \mathrm{ng} / \mathrm{ml})$, the TNF- $\alpha$ level had no considerable changes in both the TGF- $\beta 1$ and vehicle groups compared to the control group (Figure 9(a)). In contrast, IL-10 $(P<0.001$ for both cases, Figure 9(b)) and VEGF $(P<0.001$ for both cases, Figure 9(c)) levels were significantly increased in TGF- $\beta 1$ and vehicle groups compared to the control group. Premedication with PFD $(100 \mu \mathrm{g} / \mathrm{ml})$ enhanced the TNF- $\alpha$ level, but it had no statistically significant difference compared to the TGF- $\beta 1$ group $(P=0.0729$, Figure $9(\mathrm{~b}))$. Pretreatment with $C$. sativus extract $(200$ and $400 \mu \mathrm{g} / \mathrm{ml})$ significantly increased TNF- $\alpha \quad(P<0.05$ and $P<0.001$, respectively, Figure 9(a)) level and notably decreased VGEF $(P<0.001$ for both cases, Figure 9(c)) level compared to the TGF- $\beta 1$ group. However, pretreatment with a high concentration of $C$. sativus extract $(400 \mu \mathrm{g} / \mathrm{ml})$ significantly increased IL-10 level compared to the TGF- $\beta 1$ group $(P<0.001$, Figure 9(c)).

3.3.3. The Effect of C. sativus Extract and PFD on Protein Levels of $i N O S$ and Arg-1 and $i N O S / A r g-1$ Ratio. In the presence of TGF- $\beta_{1}$ stimulation $(20 \mathrm{ng} / \mathrm{ml})$, iNOS level $(P<0.001$, Figure 10(a)) and iNOS/Arg-1 ratio $(P<0.001$, Figure $10(c)$ ) were significantly diminished, but Arg-1 level 


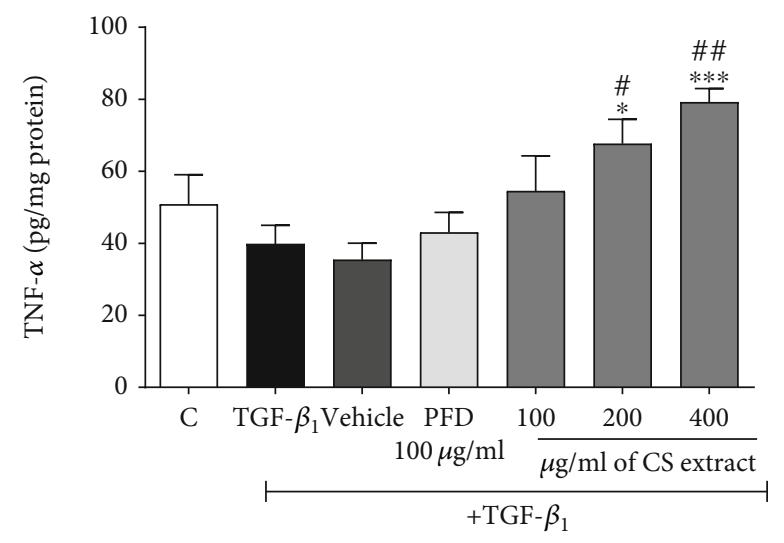

(a)

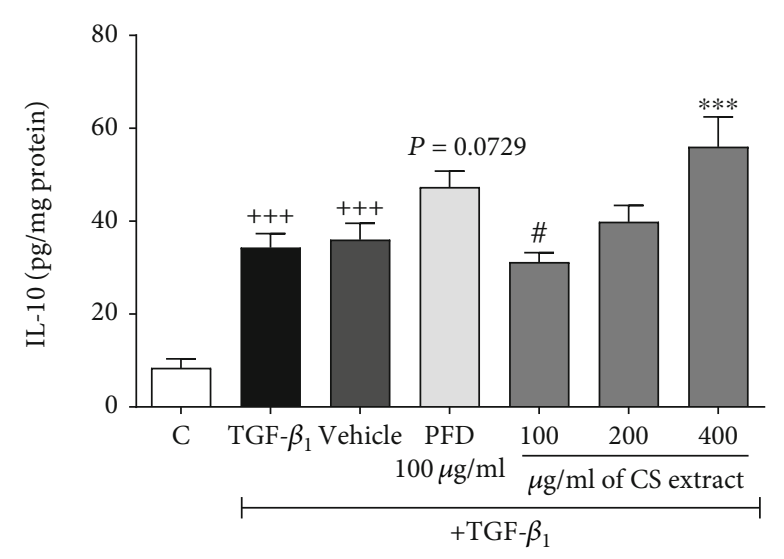

(b)

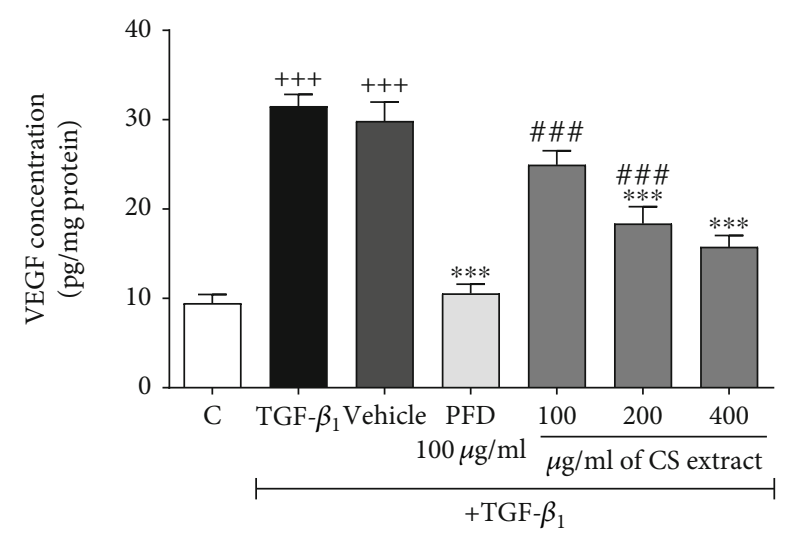

(c)

Figure 9: Effects of $C$. sativus extract $(100,200$, and $400 \mu \mathrm{g} / \mathrm{ml})$ and PFD $(100 \mu \mathrm{g} / \mathrm{ml})$ on the mRNA expression levels of proinflammatory factors of RAW 264.7 macrophage cells, including TNF- $\alpha$ (a), IL-10 (b), and VEGF (c) in the presence of TGF- $\beta$ stimulation (20 ng/ml). Data were presented as the mean $\pm \operatorname{SEM}(n=6) .{ }^{+++} P<0.001$, compared with the control group; ${ }^{* * *} P<0.001$ and ${ }^{*} P<0.05$ compared with the TGF- $\beta_{1}$ group; ${ }^{\# \#} P<0.001$ to ${ }^{\#} P<0.05$ compared with the PFD group. PFD was increased TNF- $\alpha$ level, but it had no significant difference compared to the TGF- $\beta_{1}$ group $(P=0.0729)$.

$(P<0.001$, Figure $10(\mathrm{~b}))$ was meaningfully increased in the TGF- $\beta 1$ and vehicle groups compared to the control group. Pretreatment with $C$. sativus extract $(200 \mu \mathrm{g} / \mathrm{ml}, P<0.01$, and $400 \mu \mathrm{g} / \mathrm{ml}, P<0.001)$ and PFD $(100 \mu \mathrm{g} / \mathrm{ml}, P<0.001)$ significantly increased iNOS level (Figure 10(a)) compared to the TGF- $\beta 1$ group. On the contrary, $C$. sativus extract $(200 \mu \mathrm{g} / \mathrm{ml}, P<0.05$, and $400 \mu \mathrm{g} / \mathrm{ml}, P<0.001)$ and PFD $(100 \mu \mathrm{g} / \mathrm{ml}, P<0.001)$ significantly reduced Arg-1 level (Figure $10(\mathrm{~b})$ ) in comparison to the TGF- $\beta 1$ group. Our results indicated that the highest concentration of $C$. sativus extract $(400 \mu \mathrm{g} / \mathrm{ml}, P<0.05)$ and PFD $(100 \mu \mathrm{g} / \mathrm{ml}, P<$ $0.001)$ could increase the iNOS/Arg-1 ratio compared to the TGF- $\beta 1$ group (Figure 10(c)).

\section{Discussion}

The present study evaluated the protective effects of hydroethanolic extract of $C$. sativus stigma against postoperational-induced peritoneal adhesion in a rat model. As a result, the current study demonstrated that $C$. sativus extract ameliorates postoperational-induced peritoneal adhesion development through attenuating oxidative stress
(MDA), inflammatory mediators (IL-6, TNF- $\alpha$, and $\mathrm{PGE}_{2}$ ), and fibrosis (TGF- $\beta 1$, IL-4, and PAI) and angiogenesis (VEGF) markers, while propagating antioxidant (GSH), anti-inflammatory (IL-10), and fibrinolytic (tPA) markers and $\mathrm{tPA} / \mathrm{PAI}$ ratio. Moreover, we assessed the protective and antifibrotic effects of the extract against TGF- $\beta 1$-induced fibrosis in RAW 264.7 murine macrophage cell line. Briefly, we revealed that the extract, without any toxicity, modulated the levels of cell proliferation and inflammatory (TNF- $\alpha$ ), angiogenesis (VEGF), anti-inflammatory (IL-10), M1 (iNOS), and M2 (Arg-1) biomarkers and iNOS/Arg-1 ratio towards antifibrotic M1 phenotype of macrophage, in a concentration-dependent manner.

Numerous models have been suggested to evaluate postoperative peritoneal adhesion, including uterine horn damage, bacterial infection, and scarping model [47, 48]. In the current study, we used the scraping model due to the most similarity between the adhesion development by this model and abdominopelvic surgery [49, 50]. Furthermore, we scored the adhesions from zero to four using the Nair et al. and adhesion scheme scoring methods [25, 32, 50]. Our macroscopic data revealed that the adhesion score was 


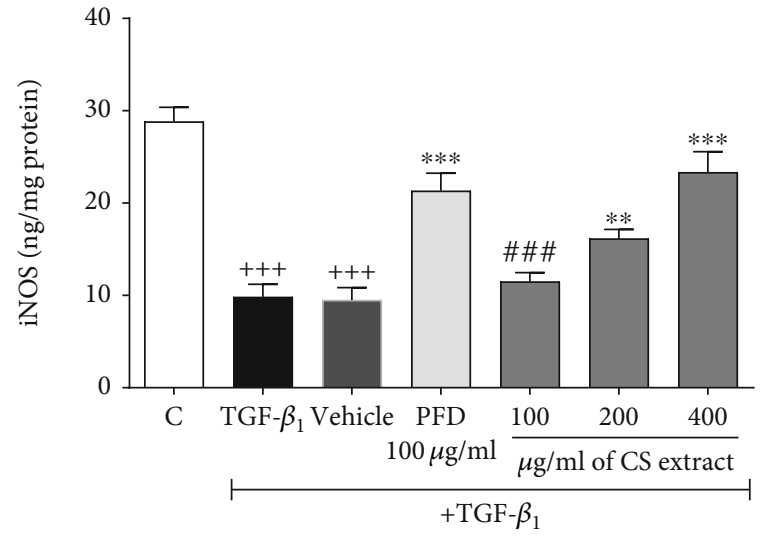

(a)

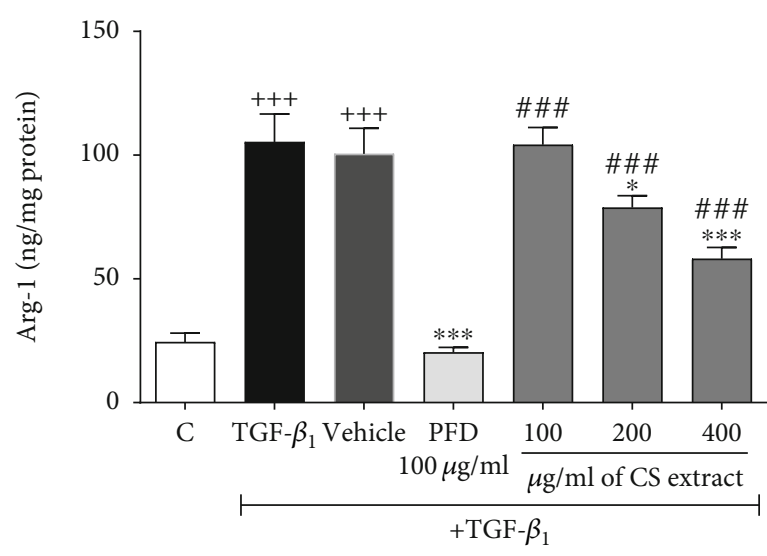

(b)

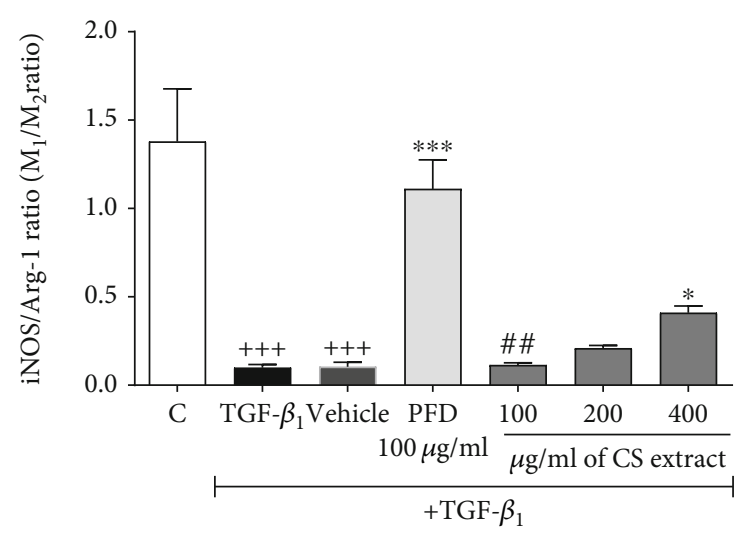

(c)

Figure 10: Effects of C. sativus extract $(100,200$, and $400 \mu \mathrm{g} / \mathrm{ml})$ and PFD $(100 \mu \mathrm{g} / \mathrm{ml})$ on the iNOS and Arg-1 levels iNOS/Arg-1 ratio of RAW 264.7 macrophage cells. (a) iNOS, (b) Arg-1, and (c) iNOS/Arg-1 ratio in the presence of TGF- $\beta$ stimulation (20 ng/ml). Data were presented as the mean \pm SEM $(n=6) .{ }^{+++} P<0.001$, compared with the control group; ${ }^{* * *} P<0.001$ and ${ }^{*} P<0.05$ compared with the TGF$\beta_{1}$ group; ${ }^{\# \# \#} P<0.001$ and ${ }^{\# \#} P<0.01$ compared with the PFD group.

significantly increased in the control group, while $C$. sativus $(0.25$ and $0.5 \% w / v)$ concentration-dependently reduced the adhesion formation following postoperational-induced peritoneal adhesion in the rat. Our previous study also reported that the adhesion score is enhanced in the control group that received postoperative-induced peritoneal adhesion and decreased following the interventions, such as propolis, honey, and Rosmarinus officinalis treatments [2, 24, 25, 32].

In the present study, we used pirfenidone (PFD), a wellknown antifibrotic medicine, as a positive control. We showed that PFD $(7.5 \% w / v)$ provided a significant decrement in adhesion score, MDA, TNF- $\alpha, \mathrm{PGE}_{2}$, IL-6, IL-4, TGF- $\beta$, VEGF, and PAI levels, while making a significant increment in GSH, IL-10, and tPA levels as well as tPA/ PAI ratio following postoperational-induced adhesion in the rat. Moreover, following the TGF- $\beta 1$ stimulation, our cellular results also revealed that PFD $(100 \mu \mathrm{g} / \mathrm{ml})$ significantly reduced the levels of cell proliferation, VEGF, and Arg-1 but notably enhanced IL-10, iNOS, and iNOS/Arg1 ratio (M1/M2 marker) and polarized the macrophage from fibrotic phenotype towards antifibrotic M1 cells. Following our results, Bayhan et al. indicated that oral administration of PFD $(500 \mathrm{mg} / \mathrm{kg}$ po $6.25 \% \mathrm{w} / \mathrm{v})$ for two weeks significantly reduced adhesions grade and the protein concentrations and mRNA expression levels of matrix metallopeptidase-9 (MMP-9), tissue inhibitor of metalloproteinase-1 (TIMP-1), tumour necrosis factoralpha (TNF- $\alpha$ ), and TGF- $\beta 1$ [29]. Similarly, Ozbilgin and coworkers reported the protective effects of PFD $(150 \mathrm{mg} /$ animal $2 \mathrm{ml}$ of $7.5 \% \mathrm{w} / \mathrm{v}$ ) against peritoneal adhesion. In fact, they showed that PFD as the same concentration which used in our study ( $2 \mathrm{ml}$ of $7.5 \% \mathrm{w} / \mathrm{v})$ significantly diminished the peritoneal adhesion by decreasing the Th2 lymphocytes as fibrotic cells and increasing the Th1 lymphocytes as antifibrotic cells [31]. Moreover, in 2016, Hasdemir et al. also supported that intraperitoneal administration of PFD (150 mg/ animal ip $2 \mathrm{ml}$ of $7.5 \% \mathrm{w} / \mathrm{v}$ ) significantly abolished adhesion scores, fibrosis, and vascular proliferation as well as the protein concentrations of IL-17 and TGF- $\beta 1$ [30]. Intriguingly, in the cellular model of adhesion, PFD at $100 \mu \mathrm{g} / \mathrm{ml}$ reprogrammed the IL-4/IL-13-induced M2 fibrotic macrophages and polarized towards M1 cells by decreasing the levels of TGF- $\beta 1$, collagen type one, and related markers, including YM-1 and CD206 and transferrin receptors [41]. Collectively, these studies can support the results of the positive control PFD used in the current study. 
It has been demonstrated that oxidative stress is one of the major factors responsible for adhesion development. Activated oxygen and nitrogen species stimulate fibroblastic cells' growth in damaged areas and lead to fibrosis formation [51, 52]. Therefore, we investigated MDA levels as an oxidative agent and GSH as antioxidative factors. We found that $C$. sativus extract $(0.25-0.5 \% w / v \sim 25$ and $50 \mathrm{mg} / \mathrm{kg})$ meaningfully reduces MDA level and enhances GSH level following postoperational-induced peritoneal adhesion in a concentration-dependent manner. In line with our results, Ghadrdoost et al. determined that $C$. sativus extract $(30 \mathrm{mg} / \mathrm{kg})$ and crocin (15 and $30 \mathrm{mg} / \mathrm{kg}$ ) diminish lipid peroxidation by reducing the MDA level. Simultaneously, the extract and its active constituent augmented total antioxidant activity, glutathione peroxidase, glutathione reductase, and superoxide dismutase activities following the oxidative stress and spatial learning and memory deficits induced by chronic stress in rats [53].

Additionally, it has been demonstrated that $C$. sativus aqueous extract $(10,20$, and $40 \mathrm{mg} / \mathrm{kg})$ mitigated MDA and nitric oxide levels, while it appended the levels of GSH and catalase and SOD activities following streptozotocininduced diabetes in rats [54]. Akbari and coworkers figured out that $C$. sativus extract $(40 \mathrm{mg} / \mathrm{kg})$ attenuates MDA and IL-6 levels and propagates GSH level as well as glutathione peroxidase activity in exercised rats [55]. In one study, $C$. sativus stigmas and high-quality byproducts (petals +anthers-CTA) extracts $(25 \mu \mathrm{g} / \mathrm{ml})$ provided a significant decrement in ROS and lactate dehydrogenase levels in human colon cancer (HCT116) cell lines following hydrogen peroxide-induced oxidative stress. Moreover, CST and CTA alleviated MDA levels in rat colon specimens challenged with E. coli lipopolysaccharide [56]. Crocin, one of the major active constituents of C. sativus, decreased MDA and xanthine oxidase while it increased GSH levels in streptozotocin-induced diabetic rats [57]. These studies may endorse our results regarding the antioxidant effects of $C$. sativus extract.

Inflammation and inflammatory cytokines are considered one of the most critical factors responsible for postoperative adhesion formation. In damaged tissue, macrophages secret IL- 6 and TNF- $\alpha$, which cause coagulation and the formation of fibrin layers that extend adhesion [3]. By contrast, IL-10 as an anti-inflammatory cytokine inhibits the secretion of pro-inflammatory cytokines, such as IL-8, IL-6, and TNF- $\alpha$, and plasminogen activator enzymes and prevents tissue damage [53]. Therefore, we measured the effects of $C$. sativus on the levels of TNF- $\alpha$, IL- 6, IFN- $\gamma$, and PGE ${ }_{2}$ as inflammatory cytokines and IL- 4 and IL-10 concentrations as anti-inflammatory cytokines. Our results revealed that $C$. sativus extract $(0.25-0.5 \% \mathrm{w} / \mathrm{v})$ concentration-dependently reduces the levels of TNF- $\alpha$, IFN- $\gamma, \mathrm{PGE}_{2}$, IL-6, and IL-4, while making a significant increment in IL-10 level following postoperational-induced adhesion in the rat. In line with our animal results, we observed that the level of IL-10 was increased following the TGF- $\beta 1$ stimulation in the macrophage cell line. However, the level of TNF- $\alpha$ as an inflammatory cytokine was propagated at higher concentrations of the extract. In fact, this phenomenon was in contrast to the anti- inflammatory effects of the C. sativus extract observed in the animal section. It can be justified that TGF- $\beta 1$ slightly reduces the TNF- $\alpha$ and leads to provide fibrotic macrophages (M2 cells), which produce higher levels of fibrotic and angiogenesis factors, as shown in our results of Figures 9 and 10. Indeed, by TGF- $\beta 1$ stimulation, the macrophage phenotypes were polarized towards M2 cells by decreasing the level of increasing the level of Arg-1 as a marker of M2 cells and iNOS as a marker of M1 macrophage cells and iNOS/Arg-1 ratio (M1/M2 ratio). It justifies that the extract provides no inflammatory state but modulates the macrophage polarization towards nonfibrotic phenotypes that secrets higher TNF- $\alpha$ levels. Moreover, we assessed the level of IL-10 as supportive data, which endorse our vision on the direct effects of the extract on macrophage polarization and increasing the TNF- $\alpha$ level.

Christodoulou et al. demonstrated that Crocus sativus L. aqueous extract $(30,60$, and $90 \mathrm{mg} / \mathrm{kg} /$ day) reduces IL-6, TNF- $\alpha$, monocyte chemoattractant protein-1, matrix metalloproteinase- (MMP-) 2, MMP-3, and MMP-9 levels, and MMP/TIMP-2 ratio in diabetic atherosclerotic C57BL/6J wild-type mice [58]. In another study, Crocus sativus (20, 40 , and $80 \mathrm{mg} / \mathrm{kg}$ ) diminished IL-4 and NO levels, while it enhanced IFN- $\gamma$ and IFN- $\gamma /$ IL- 4 ratio levels in ovalbuminsensitised guinea pigs [59]. Faridi and coworkers suggested that hydroalcoholic extract of C. sativus $(500 \mathrm{mg} / \mathrm{kg}) \mathrm{miti}-$ gates IFN- $\gamma$ and IL-17 and augments IL-10 levels following streptozocin-induced autoimmune diabetes in $\mathrm{C} 57 \mathrm{BL} / 6$ mice [60]. However, the levels of the extract were considerably higher than what we investigated in our study. Additionally, Hemshekhar et al. reported that crocin (10 and $20 \mathrm{mg} / \mathrm{kg}$ ), one of the major active constituents of $C$. sativus, alleviates MMP-13, MMP-3, MMP-9, TNF- $\alpha$, IL- $1 \beta$, NF- $\kappa$ B, IL-6, COX-2, PGE 2 , and ROS levels following Freund's complete adjuvant- (FCA-) induced arthritis in rats [61]. In another study, crocin (100 and $200 \mathrm{ppm} \sim 1$ and $2 \% \mathrm{w} / \mathrm{v}$ ) made a significant decrement in the levels of mRNA expression of TNF- $\alpha$, IL- $1 \beta$, IL- 6 , IFN- $\gamma$, NF- $\kappa$ B, COX- 2 , and iNOS and propagated Nrf2 mRNA expression in the colorectal mucosa following dextran sodium sulfate-induced colitis [62]. These studies may support our results regarding the anti-inflammatory properties of $C$. sativus extract.

The previous human and animal studies indicated that the levels of TGF- $\beta$ are significantly increased in the peritoneal adhesions $[2,24,50]$. TGF- $\beta$ is a suppressive and fibrotic cytokine that controls reproduction, differentiation, cell apoptosis, and wound healing. The active form of TGF- $\beta$ increases the secretion of the extracellular matrix, leading to the formation of adhesion $[3,63]$. Vascular endothelial growth factor (VEGF) is another growth factor and potent mitogen for endothelial cells and a vital angiogenesis factor, which is essential for wound healing and adhesion formation $[2,24,50]$. In fact, VEGF production is stimulated by lactate in macrophages, and lactate accumulation plays a critical role in adhesion development [2, 3, 24, 50]. It has been emphasised that the anti-VEGF monoclonal antibody decreases the postoperational peritoneal adhesion in mice [64]. The current study results figured out that C. sativus extract $(0.25-0.5 \% \quad w / v \sim 25$ and $50 \mathrm{mg} / \mathrm{kg})$ provided a 


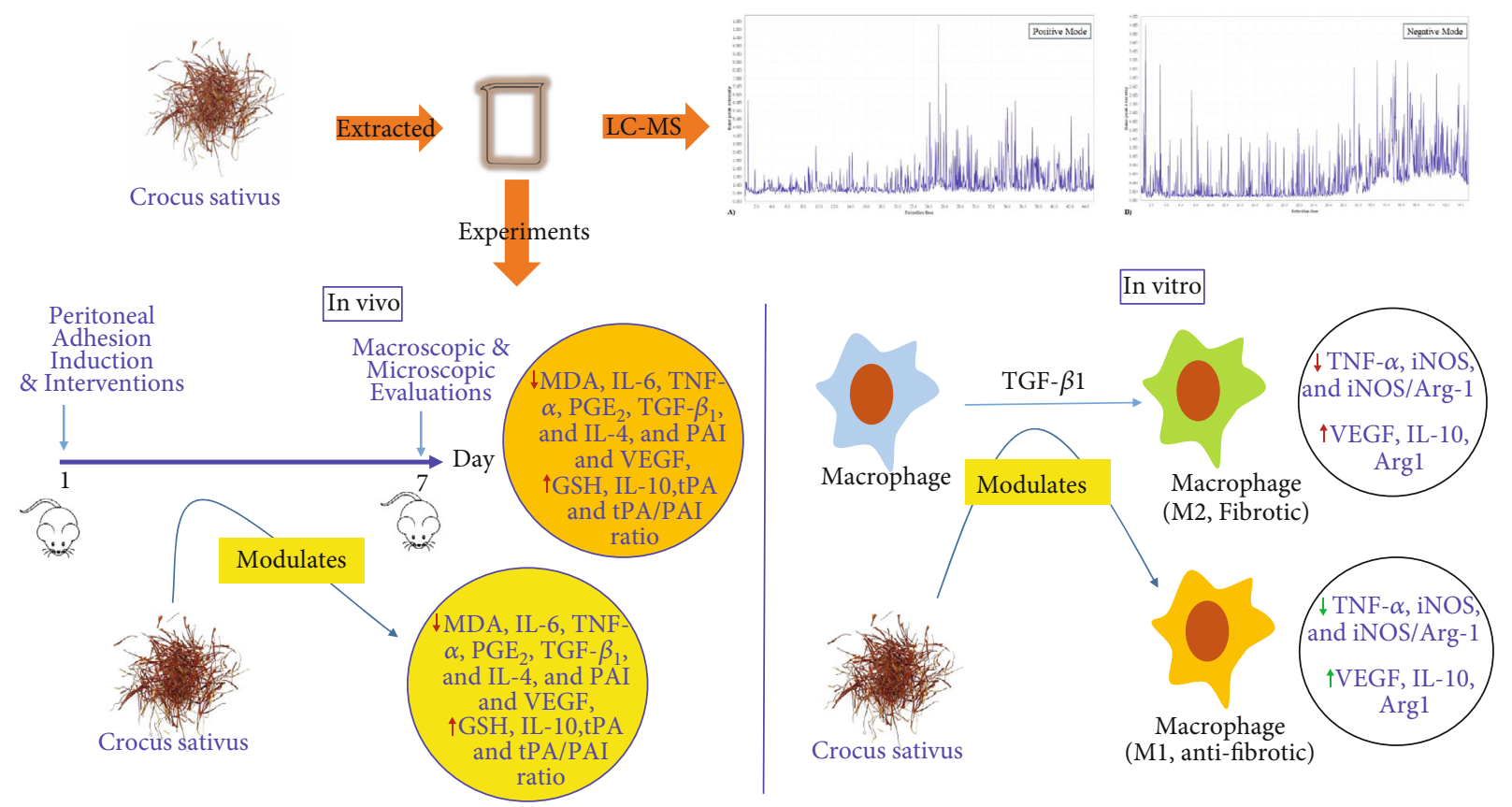

FIGURE 11: Preventive effects of C. sativus extract against postsurgical-induced peritoneal adhesion.

significant and concentration-dependent decrement in TGF$\beta$ and VEGF levels following the postoperational peritoneal adhesion. Interestingly, our in vitro study found that VEGF level was also meaningfully abrogated by $C$. sativus extract in a concentration-dependent manner.

In line with our results, Alemzadeh and Oryan investigated that $C$. sativus extract ( $20 \% w / w$; topically) diminishes the expression of IL- $1 \beta$ and TGF- $\beta 1$ and improves wound healing following the burn wounds in rats [65]. Additionally, crocin $(20 \mathrm{mg} / \mathrm{kg})$ mitigated TGF- $\beta$, NF- $\kappa$ B, and IL-6 expression levels following streptozocin-induced diabetic nephropathy in rats [66]. Algandaby also showed that crocin (25 and $100 \mathrm{mg} / \mathrm{kg}$ ) attenuates the expression of TGF- $\beta$, alpha-smooth muscle actin ( $\alpha$-SMA) and collagen 1- $\alpha$, NF$\kappa \mathrm{B}$, COX-2, IL- $1 \beta$, and TNF- $\alpha$ following thioacetamideinduced liver fibrosis in mice [67]. Kermani and coworkers demonstrated that $C$. sativus $(100 \mathrm{mg} /$ day) reduces VEGF, IL-2, and IL- $1 \beta$ while enhancing IL-10 levels compared to the placebo group in metabolic syndrome patients [68]. Furthermore, C. sativus aqueous extract $(400$ and $800 \mu \mathrm{g} / \mathrm{ml}$ ) attenuated the expression levels of VEGF-A and VEGF-2 in the MCF-7 cell line and prevented angiogenesis [69]. Additionally, crocin $(25 \mathrm{mg} / \mathrm{kg})$ mitigated VEGF, IL-6, IFN- $\gamma$, and TNF- $\alpha$ levels in a mouse model of endometriosis [70]. In another study, crocin $(250$ and $500 \mu \mathrm{g} / \mathrm{kg})$ attenuated VEGF, MMP-2, and MMP-9 expressions and TNF- $\alpha$ and IL-6 levels while it elevated IL-10 level in melanoma metastatic model in C57BL/6 mice [71]. These studies may endorse our animal and cellular results regarding the antifibrotic and antiangiogenesis effects of the extract.

Tissue plasminogen activator (tPA) is classified as a serine protease that prevents the progression of mesothelial cell adhesion by inhibiting plasminogen transformation to plasmin. In low tPA level condition, fibrin masses form a clot attacked by fibroblasts, collagens, and other proteins that lead to adhesion formation [72]. Plasminogen activator inhibitor (PAI), which is present in plasma, inhibits the tPA. Increasing the PAI level and decreasing the tPA level and tPA/PAI ratio are considered adhesion development causes $[3,73]$. In one study, Atta and coworkers found lower TGF- $\beta 1$ and PAI and higher PA levels in the group with a lower rate of postoperative adhesion formation in rats [74]. Therefore, we determined the levels of TPA, PAI and the ratio of TPA/PAI. We found that C. sativus $(0.25-0.5 \% w / v$ $\sim 25$ and $50 \mathrm{mg} / \mathrm{kg}$ ) mitigates PAI level and propagates tPA and TPA/PAI ratio levels in a concentration-dependent manner following the postoperational induced peritoneal adhesion. Tsantarliotou and coworkers suggested that crocin at both low and high doses (10 and $100 \mathrm{mg} / \mathrm{kg}$ ) could diminish PAI-1 levels in the liver and brain tissue following lipopolysaccharide-induced thrombosis in rats [75].

\section{Conclusion}

In summary, our results revealed that $C$. sativus could prevent postoperative peritoneal adhesion through attenuating adhesion score, oxidative stress, inflammatory cytokines, fibrosis, and angiogenesis markers, while propagating antioxidant and anti-inflammatory markers and tPA (Figure 11). Moreover, the current study indicated that $C$. sativus reduces peritoneal adhesion formation by modulating the macrophage polarization from M2 towards M1 cells (Figure 11). It could be concluded that $C$. sativus may be the right candidate for preventing postoperative peritoneal adhesion. 


$\begin{array}{ll}\text { Abbreviations } \\ \text { COX2: } & \text { Cyclooxygenase-2 } \\ \text { GSH: } & \text { Glutathione } \\ \text { IFN- } \gamma: & \text { Interferon-gamma } \\ \text { IL-10: } & \text { Interleukin-10 } \\ \text { IL-4: } & \text { Interleukin-4 } \\ \text { IL-6: } & \text { Interleukin-6 } \\ \text { iNOS: } & \text { Nitric oxide synthase } \\ \text { MDA: } & \text { Malondialdehyde } \\ \text { MMP: } & \text { Matrix metallopeptidase } \\ \text { NF- } \kappa \text { B: } & \text { Nuclear factor kappa-light-chain-enhancer of } \\ & \text { activated B cells } \\ \text { NO: } & \text { Nitric oxide } \\ \text { PA: } & \text { Plasminogen activator } \\ \text { PFD: } & \text { Pirfenidone } \\ \text { PGE }: & \text { Prostaglandin E2 } \\ \text { SOD: } & \text { Superoxide dismutase } \\ \text { TAP: } & \text { Tissue plasminogen activator } \\ \text { TGF- } \beta: & \text { Transforming growth factor-beta } \\ \text { TIMP-2: } & \text { Tissue inhibitor of metalloproteinases-2 } \\ \text { TIMPs: } & \text { The tissue inhibitors of metalloproteinases } \\ \text { TNF- } \alpha: & \text { Tumour necrosis factor-alpha } \\ \text { VEGF: } & \text { Vascular endothelial growth factor } \\ \alpha-S M A: & \text { Alpha-smooth muscle actin. } \\ & \end{array}$

\section{Data Availability}

The data used to support the findings of this study are available from the corresponding author upon reasonable request.

\section{Conflicts of Interest}

The authors declare that they have no conflict of interest to disclose.

\section{Authors' Contributions}

Pouria Rahmanian Devin, Hassan Rakhshandeh, and Vafa Baradaran Rahimi had equal contributions as the first authors.

\section{Acknowledgments}

This study was supported by the research council of Mashhad University of Medical Sciences.

\section{References}

[1] K. M. Braun and M. P. Diamond, "The biology of adhesion formation in the peritoneal cavity," Seminars in Pediatric Surgery, vol. 23, no. 6, pp. 336-343, 2014.

[2] Y. Roohbakhsh, V. B. Rahimi, S. Silakhori et al., "Evaluation of the effects of peritoneal lavage with Rosmarinus officinalis extract against the prevention of postsurgical-induced peritoneal adhesion," Planta Medica, vol. 86, no. 6, pp. 405-414, 2020.

[3] M. W. Stommel, C. Strik, and H. van Goor, "Response to pathological processes in the peritoneal cavity-sepsis, tumours, adhesions, and ascites," Seminars in Pediatric Surgery, vol. 23, no. 6, pp. 331-335, 2014.

[4] Z. Alpay, G. M. Saed, and M. P. Diamond, "Postoperative adhesions: from formation to prevention," Seminars in Reproductive Medicine, vol. 26, no. 4, pp. 313-321, 2008.

[5] R. C. Lantz, G. J. Chen, A. M. Solyom, S. D. Jolad, and B. N. Timmermann, "The effect of turmeric extracts on inflammatory mediator production," Phytomedicine, vol. 12, no. 6-7, pp. 445-452, 2005.

[6] Y. Zhang, X. Li, Q. Zhang et al., "Berberine hydrochloride prevents postsurgery intestinal adhesion and inflammation in rats," The Journal of Pharmacology and Experimental Therapeutics, vol. 349, no. 3, pp. 417-426, 2014.

[7] V. B. Rahimi, A. Rajabian, H. Rajabi et al., "The effects of hydro-ethanolic extract of Capparis spinosa (C. spinosa) on lipopolysaccharide (LPS)-induced inflammation and cognitive impairment: Evidence from in vivo and in vitro studies," Journal of Ethnopharmacology, vol. 256, p. 112706, 2020.

[8] V. R. Askari, V. B. Rahimi, S. A. Tabatabaee, and R. ShafieeNick, "Combination of imipramine, a sphingomyelinase inhibitor, and $\beta$-caryophyllene improve their therapeutic effects on experimental autoimmune encephalomyelitis (EAE)," International Immunopharmacology, vol. 77, p. 105923, 2019.

[9] V. R. Askari, V. B. Rahimi, R. Zargarani, R. Ghodsi, M. Boskabady, and M. H. Boskabady, "Anti-oxidant and anti-inflammatory effects of auraptene on phytohemagglutinin (PHA)-induced inflammation in human lymphocytes," Pharmacological Reports, vol. 73, no. 1, pp. 154-162, 2021.

[10] N. Chegini, “TGF- $\beta$ system: the principal profibrotic mediator of peritoneal adhesion formation," Seminars in Reproductive Medicine, vol. 26, no. 4, pp. 298-312, 2008.

[11] V. I. Shavell, G. M. Saed, and M. P. Diamond, "Review: cellular metabolism: contribution to postoperative adhesion development," Reproductive Sciences, vol. 16, no. 7, pp. 627-634, 2009.

[12] B. C. Ward and A. Panitch, "Abdominal adhesions: current and novel therapies," The Journal of Surgical Research, vol. 165, no. 1, pp. 91-111, 2011.

[13] D. Robertson, G. Lefebvre, N. Leyland et al., "Clinical practice gynaecology, adhesion prevention in gynaecological surgery," Journal of Obstetrics and Gynaecology Canada, vol. 32, no. 6, pp. 598-602, 2010.

[14] A. H. DeCherney and G. S. diZerega, "Clinical problem of intraperitoneal postsurgical adhesion formation following general surgery and the use of adhesion prevention barriers," The Surgical Clinics of North America, vol. 77, no. 3, pp. 671-688, 1997.

[15] W. Arung, M. Meurisse, and O. Detry, "Pathophysiology and prevention of postoperative peritoneal adhesions," World Journal of Gastroenterology, vol. 17, no. 41, pp. 4545-4553, 2011.

[16] F. I. Abdullaev, "Cancer chemopreventive and tumoricidal properties of saffron (Crocus sativus L.)," Experimental Biology and Medicine (Maywood, N.J.), vol. 227, no. 1, pp. 20-25, 2002.

[17] S. Rahaiee, S. Moini, M. Hashemi, and S. A. Shojaosadati, "Evaluation of antioxidant activities of bioactive compounds and various extracts obtained from saffron (Crocus sativus L.): a review," Journal of Food Science and Technology, vol. 52, no. 4, pp. 1881-1888, 2015.

[18] S. I. Bukhari, M. Manzoor, and M. K. Dhar, "A comprehensive review of the pharmacological potential of Crocus sativus and 
its bioactive apocarotenoids," Biomedicine \& Pharmacotherapy, vol. 98, pp. 733-745, 2018.

[19] A. Milajerdi, V. Bitarafan, and M. Mahmoudi, "a review on the effects of saffron extract and its constituents on factors related to neurologic, cardiovascular and gastrointestinal diseases," Journal of Medicinal Plants, vol. 14, pp. 9-28, 2015.

[20] M. R. Khazdair, M. H. Boskabady, M. Hosseini, R. Rezaee, and A. M. Tsatsakis, "The effects of Crocus sativus (saffron) and its constituents on nervous system: a review," Avicenna journal of phytomedicine, vol. 5, no. 5, pp. 376-391, 2015.

[21] S. Kianbakht, "A systematic review on pharmacology of saffron and its active constituents," Journal of Medicinal Plants, vol. 28, pp. 1-27, 2008.

[22] A. R. Khorasany and H. Hosseinzadeh, "Therapeutic effects of saffron (Crocus sativus L.) in digestive disorders: a review," Iranian journal of basic medical sciences, vol. 19, no. 5, pp. 455-469, 2016.

[23] V. B. Rahimi, V. R. Askari, M. Hosseini, B. S. Yousefsani, and H. R. Sadeghnia, "Anticonvulsant activity of Viola tricolor against seizures induced by pentylenetetrazol and maximal electroshock in mice," Iranian journal of medical sciences, vol. 44, no. 3, pp. 220-226, 2019.

[24] V. R. Askari, V. B. Rahimi, P. Zamani et al., "Evaluation of the effects of Iranian propolis on the severity of post operationalinduced peritoneal adhesion in rats," Biomedicine \& Pharmacotherapy, vol. 99, pp. 346-353, 2018.

[25] V. B. Rahimi, R. Shirazinia, N. Fereydouni et al., "Comparison of honey and dextrose solution on post-operative peritoneal adhesion in rat model," Biomedicine \& Pharmacotherapy, vol. 92, pp. 849-855, 2017.

[26] M. D. Sarap, K. S. Scher, and C. W. Jones, “Anaerobic coverage for wound prophylaxis: Comparison of cefazolin and cefoxitin," American Journal of Surgery, vol. 151, no. 2, pp. 213215, 1986.

[27] D. L. Cavanaugh, J. Berry, S. R. Yarboro, and L. E. Dahners, "Better prophylaxis against surgical site infection with local as well as systemic antibiotics. An in vivo study," The Journal of Bone and Joint Surgery. American Volume, vol. 91, no. 8, pp. 1907-1912, 2009.

[28] P. Liang, W. Shan, and Z. Zuo, "Perioperative use of cefazolin ameliorates postoperative cognitive dysfunction but induces gut inflammation in mice," Journal of neuroinflammation, vol. 15, no. 1, p. 235, 2018.

[29] Z. Bayhan, S. Zeren, F. E. Kocak et al., "Antiadhesive and anti-inflammatory effects of pirfenidone in postoperative intra-abdominal adhesion in an experimental rat model," The Journal of Surgical Research, vol. 201, no. 2, pp. 348355, 2016.

[30] P. S. Hasdemir, M. Ozkut, T. Guvenal et al., "Effect of pirfenidone on vascular proliferation, inflammation and fibrosis in an abdominal adhesion rat model," Journal of Investigative Surgery, vol. 30, no. 1, pp. 26-32, 2017.

[31] K. Ozbilgin, M. A. Üner, M. Ozkut, and P. S. Hasdemir, “The effects of pirfenidone on Thelper cells in prevention of intraperitoneal adhesions," The Kaohsiung Journal of Medical Sciences, vol. 33, no. 6, pp. 271-276, 2017.

[32] S. K. Nair, I. K. Bhat, and A. L. Aurora, "Role of proteolytic enzyme in the prevention of postoperative intraperitoneal adhesions," Archives of Surgery, vol. 108, no. 6, pp. 849-853, 1974.
[33] C. Dees, A. Akhmetshina, P. Zerr et al., "Platelet-derived serotonin links vascular disease and tissue fibrosis," Journal of Experimental Medicine, vol. 208, no. 5, pp. 961-972, 2011.

[34] A. Jaafari, V. Baradaran Rahimi, N. Vahdati-Mashhadian et al., "Evaluation of the Therapeutic Effects of the Hydroethanolic Extract of Portulaca oleracea on Surgical-Induced Peritoneal Adhesion," Mediators of Inflammation, vol. 2021, Article ID 8437753, 18 pages, 2021.

[35] M. Hu, Y. Zhang, X. Guo et al., "Perturbed ovarian and uterine glucocorticoid receptor signaling accompanies the balanced regulation of mitochondrial function and $\mathrm{NF} \kappa \mathrm{B}$-mediated inflammation under conditions of hyperandrogenism and insulin resistance," Life Sciences, vol. 232, p. 116681, 2019.

[36] V. B. Rahimi, V. R. Askari, and S. H. Mousavi, "Ellagic acid reveals promising anti-aging effects against d-galactoseinduced aging on human neuroblastoma cell line, SH-SY5Y: a mechanistic study," Biomedicine \& Pharmacotherapy, vol. 108, pp. 1712-1724, 2018.

[37] V. R. Askari, V. Baradaran Rahimi, A. Assaran, M. Iranshahi, and M. H. Boskabady, "Evaluation of the anti-oxidant and anti-inflammatory effects of the methanolic extract of Ferula szowitsiana root on PHA-induced inflammation in human lymphocytes," Drug and Chemical Toxicology, vol. 43, no. 4, pp. 353-360, 2020.

[38] V. B. Rahimi, V. R. Askari, R. Shirazinia et al., "Protective effects of hydro-ethanolic extract of Terminalia chebula on primary microglia cells and their polarization $\left(\mathrm{M}_{1} / \mathrm{M}_{2}\right.$ balance)," Multiple Sclerosis and Related Disorders, vol. 25, pp. 5-13, 2018.

[39] V. Baradaran Rahimi, H. Rakhshandeh, F. Raucci et al., “Antiinflammatory and anti-oxidant activity of Portulaca oleracea extract on LPS-induced rat lung injury," Molecules, vol. 24, no. 1, p. 139, 2019.

[40] F. Liu, H. Qiu, M. Xue et al., "MSC-secreted TGF- $\beta$ regulates lipopolysaccharide-stimulated macrophage M2-like polarization via the Akt/FoxO1 pathway," Stem Cell Research \& Therapy, vol. 10, no. 1, p. 345, 2019.

[41] M. Toda, S. Mizuguchi, Y. Minamiyama et al., "Pirfenidone suppresses polarization to M2 phenotype macrophages and the fibrogenic activity of rat lung fibroblasts," Journal of Clinical Biochemistry and Nutrition, vol. 63, no. 1, pp. 58-65, 2018.

[42] F. Zhang, H. Wang, X. Wang et al., “TGF- $\beta$ induces M2-like macrophage polarization via SNAIL-mediated suppression of a pro-inflammatory phenotype," Oncotarget, vol. 7, no. 32, pp. 52294-52306, 2016.

[43] V. B. Rahim, M. T. Khammar, H. Rakhshandeh, A. SamzadehKermani, A. Hosseini, and V. R. Askari, "Crocin protects cardiomyocytes against LPS-induced inflammation," Pharmacological Reports, vol. 71, no. 6, pp. 1228-1234, 2019.

[44] M. J. Curtis, R. A. Bond, D. Spina et al., "Experimental design and analysis and their reporting: new guidance for publication in BJP," British Journal of Pharmacology, vol. 172, no. 14, pp. 3461-3471, 2015.

[45] C. H. George, S. C. Stanford, S. Alexander et al., "Updating the guidelines for data transparency in the British Journal of Pharmacology - data sharing and the use of scatter plots instead of bar charts," British Journal of Pharmacology, vol. 174, no. 17, pp. 2801-2804, 2017.

[46] S. P. H. Alexander, R. E. Roberts, B. R. Broughton et al., "Goals and practicalities of immunoblotting and immunohistochemistry: a guide for submission to the British Journal of 
Pharmacology," British Journal of Pharmacology, vol. 175, no. 3, pp. 407-411, 2018.

[47] H. A. Kayaoglu, N. Ozkan, E. Yenidogan, and R. D. Koseoglu, "Effect of antibiotic lavage in adhesion prevention in bacterial peritonitis," Ulusal Travma ve Acil Cerrahi Dergisi, vol. 19, no. 3, pp. 189-194, 2013.

[48] Y. Yue, S. Yan, H. Li, Y. Zong, J. Yue, and L. Zeng, "The role of oral fluvastatin on postoperative peritoneal adhesion formation in an experimental rat model," Acta Chirurgica Belgica, vol. 118, no. 6, pp. 372-379, 2018.

[49] L. Allegre, I. Le Teuff, S. Leprince et al., "A new bioabsorbable polymer film to prevent peritoneal adhesions validated in a post-surgical animal model," PLoS One, vol. 13, no. 11, 2018.

[50] M. Ghadiri, V. B. Rahimi, E. Moradi et al., "Standardised pomegranate peel extract lavage prevents postoperative peritoneal adhesion by regulating TGF- $\beta$ and VEGF levels," Inflammopharmacology, vol. 29, no. 3, pp. 855-868, 2021.

[51] G. Wei, Y. Wu, Q. Gao et al., "Effect of emodin on preventing postoperative intra-abdominal adhesion formation," Oxidative Medicine and Cellular Longevity, vol. 2017, Article ID 1740317, 12 pages, 2017.

[52] C. Ara, A. B. Karabulut, H. Kirimlioglu, M. Yilmaz, V. Kirimliglu, and S. Yilmaz, "Protective effect of aminoguanidine against oxidative stress in an experimental peritoneal adhesion model in rats," Cell Biochemistry and Function, vol. 24, no. 5, pp. 443-448, 2006.

[53] B. Ghadrdoost, A. A. Vafaei, A. Rashidy-Pour et al., "Protective effects of saffron extract and its active constituent crocin against oxidative stress and spatial learning and memory deficits induced by chronic stress in rats," European Journal of Pharmacology, vol. 667, no. 1-3, pp. 222-229, 2011.

[54] S. Samarghandian, M. Azimi-Nezhad, and T. Farkhondeh, "Immunomodulatory and antioxidant effects of saffron aqueous extract (Crocus sativus L.) on streptozotocin-induced diabetes in rats," Indian Heart Journal, vol. 69, no. 2, pp. 151-159, 2017.

[55] M. Akbari-Fakhrabadi, M. Najafi, S. Mortazavian, M. Rasouli, A. H. Memari, and F. Shidfar, "Effect of saffron (Crocus sativus L.) and endurance training on mitochondrial biogenesis, endurance capacity, inflammation, antioxidant, and metabolic biomarkers in Wistar rats," Journal of Food Biochemistry, vol. 43 , no. $8,2019$.

[56] L. Menghini, L. Leporini, G. Vecchiotti et al., "Crocus sativus L. stigmas and byproducts: Qualitative fingerprint, antioxidant potentials and enzyme inhibitory activities," Food Research International, vol. 109, pp. 91-98, 2018.

[57] E. Altinoz, Z. Oner, H. Elbe, Y. I. L. M. A. Z. Cigremis, and Y. Turkoz, "Protective effects of saffron (its active constituent, crocin) on nephropathy in streptozotocin-induced diabetic rats," Human \& Experimental Toxicology, vol. 34, no. 2, pp. 127-134, 2015.

[58] E. Christodoulou, N. P. E. Kadoglou, M. Stasinopoulou et al., "Crocus sativus L. aqueous extract reduces atherogenesis, increases atherosclerotic plaque stability and improves glucose control in diabetic atherosclerotic animals," Atherosclerosis, vol. 268, pp. 207-214, 2018.

[59] G. Byrami, M. H. Boskabady, S. Jalali, and T. Farkhondeh, "The effect of the extract of Crocus sativus on tracheal responsiveness and plasma levels of IL-4, IFN- $\gamma$, total NO and nitrite in ovalbumin sensitized Guinea-pigs," Journal of Ethnopharmacology, vol. 147, no. 2, pp. 530-535, 2013.
[60] S. Faridi, N. Delirezh, and S. M. Abtahi Froushani, "Beneficial effects of hydroalcoholic extract of saffron in alleviating experimental autoimmune diabetes in C57bl/6 mice," Iranian Journal of Allergy, Asthma, and Immunology, vol. 18, no. 1, pp. 3847, 2019.

[61] M. Hemshekhar, M. S. Santhosh, K. Sunitha et al., "A dietary colorant crocin mitigates arthritis and associated secondary complications by modulating cartilage deteriorating enzymes, inflammatory mediators and antioxidant status," Biochimie, vol. 94, no. 12, pp. 2723-2733, 2012.

[62] K. Kawabata, N. H. Tung, Y. Shoyama, S. Sugie, T. Mori, and T. Tanaka, "Dietary crocin inhibits colitis and colitisassociated colorectal carcinogenesis in male ICR mice," Evidence-based Complementary and Alternative Medicine, vol. 2012, Article ID 820415, 13 pages, 2012.

[63] M. Kianmehr, A. Rezaei, M. Hosseini et al., "Immunomodulatory effect of characterized extract of Zataria multiflora on Th1, Th2 and Th17 in normal and Th2 polarization state," Food and Chemical Toxicology, vol. 99, pp. 119127, 2017.

[64] R. A. Cahill, J. H. Wang, S. Soohkai, and H. P. Redmond, "Mast cells facilitate local VEGF release as an early event in the pathogenesis of postoperative peritoneal adhesions," Surgery, vol. 140, no. 1, pp. 108-112, 2006.

[65] E. Alemzadeh and A. Oryan, "Effectiveness of a Crocus sativus extract on burn wounds in rats," Planta Medica, vol. 84, no. 16, pp. 1191-1200, 2018.

[66] H. O. Abou-Hany, H. Atef, E. Said, H. A. Elkashef, and H. A. Salem, "Crocin mediated amelioration of oxidative burden and inflammatory cascade suppresses diabetic nephropathy progression in diabetic rats," Chemico-Biological Interactions, vol. 284, pp. 90-100, 2018.

[67] M. M. Algandaby, "Antifibrotic effects of crocin on thioacetamide-induced liver fibrosis in mice," Saudi journal of biological sciences, vol. 25, no. 4, pp. 747-754, 2018.

[68] T. Kermani, M. Zebarjadi, H. Mehrad-Majd et al., "Antiinflammatory effect of Crocus sativus on serum cytokine levels in subjects with metabolic syndrome: a randomized, doubleblind, Placebo- Controlled Trial," Current clinical pharmacology, vol. 12, no. 2, pp. 122-126, 2017.

[69] M. Mousavi and J. Baharara, "Effect of Crocus sativus L. on expression of VEGF-A and VEGFR-2 genes (angiogenic biomarkers) in MCF-7 cell line," Zahedan Journal of Research in Medical Sciences, vol. 16, no. 12, pp. 8-14, 2013.

[70] Y. Liu, X. Qin, and X. Lu, “Crocin improves endometriosis by inhibiting cell proliferation and the release of inflammatory factors," Biomedicine \& Pharmacotherapy, vol. 106, pp. 1678-1685, 2018.

[71] H. A. Bakshi, F. L. Hakkim, S. Sam, F. Javid, and L. Rashan, "Dietary crocin reverses melanoma metastasis," Journal of Biomedical Research, vol. 32, 2018.

[72] M. T. Lee, C. C. Lee, H. M. Wang et al., "Hypothermia increases tissue plasminogen activator expression and decreases post-operative intra-abdominal adhesion," PLoS One, vol. 11, no. 9, 2016.

[73] G. M. Saed and M. P. Diamond, "Modulation of the expression of tissue plasminogen activator and its inhibitor by hypoxia in human peritoneal and adhesion fibroblasts," Fertility and Sterility, vol. 79, no. 1, pp. 164-168, 2003.

[74] H. M. Atta, A. Al-Hendy, M. A. El-Rehany et al., "Adenovirusmediated overexpression of human tissue plasminogen 
activator prevents peritoneal adhesion formation/reformation in rats," Surgery, vol. 146, no. 1, pp. 12-17, 2009.

[75] M. P. Tsantarliotou, S. N. Lavrentiadou, D. A. Psalla et al., "Suppression of plasminogen activator inhibitor-1 (PAI-1) activity by crocin ameliorates lipopolysaccharide-induced thrombosis in rats," Food and Chemical Toxicology, vol. 125, pp. 190-197, 2019.

[76] A. Bolhassani, A. Khavari, and S. Z. Bathaie, "Saffron and natural carotenoids: biochemical activities and anti-tumor effects," Biochimica et Biophysica Acta (Bba)-reviews on cancer, vol. 1845, no. 1, pp. 20-30, 2014.

[77] L. Sabatino, M. Scordino, M. Gargano, A. Belligno, P. Traulo, and G. Gagliano, "HPLC/PDA/ESI-MS evaluation of saffron (Crocus sativusL.) adulteration," Natural Product Communications, vol. 6, no. 12, 2011.

[78] S. A. Baba, A. H. Malik, Z. A. Wani et al., "Phytochemical analysis and antioxidant activity of different tissue types of Crocus sativus and oxidative stress alleviating potential of saffron extract in plants, bacteria, and yeast," South African Journal of Botany, vol. 99, pp. 80-87, 2015.

[79] M. Guijarro-Díez, L. Nozal, M. L. Marina, and A. L. Crego, "Metabolomic fingerprinting of saffron by LC/MS: novel authenticity markers," Analytical and Bioanalytical Chemistry, vol. 407, no. 23, pp. 7197-7213, 2015.

[80] A. Termentzi and E. Kokkalou, "LC-DAD-MS (ESI+) analysis and antioxidant capacity of Crocus sativus petal extracts," Planta Medica, vol. 74, no. 5, pp. 573-581, 2008. 